\title{
A Dynamic Syntax modelling of Japanese and Rangi clefts: Parsing incrementality and the growth of interpretation
}

\author{
Tohru Seraku and Hannah Gibson
}

\begin{abstract}
Japanese and Rangi (a Bantu language) employ cleft constructions to encode pragmatic functions relating to discourse salience. In Japanese, a cleft is formed through the nominaliser 'no,' the topic marker 'wa,' and the copula 'da.' In Rangi, a cleft is formed through the copula 'nf́' which appears before the focus. This article provides a description of clefts in these two unrelated languages; in particular, Rangi clefts have been understudied, and our description represents a first systematic treatment. The article also develops an account from the new perspective of how a cleft string is parsed left-to-right in an online manner (Dynamic Syntax; Cann, R. et al. 2005. The Dynamics of Language. Elsevier). We propose that a number of seemingly idiosyncratic syntactic properties of clefts in these languages (including new data on case-marking patterns of foci in Japanese clefts and the auxiliary placement in Rangi clefts) can be accounted for by reference to left-to-right, online parsing, and the restriction on structural underspecification that is an integral part of the framework. Our account also models parallelisms and differences in Japanese and Rangi clefts in terms of parsing-dynamics.
\end{abstract}

Keywords: cleft construction; Japanese; Rangi; Dynamic Syntax; incrementality

\section{Introduction}

Since Chomsky (1965), the competence/performance distinction has been a leading methodological principle in theoretical syntax. In mainstream generative grammar (Chomsky 1981, 1995), competence is a set of principles and rules which models the tacit knowledge of grammar in the human mind. Under this view, competence is defined independently from language use; the research goal of generative grammar, therefore, is to logically characterise the system of competence, setting aside the issue of how this is put into use. In other versions of generative grammar, such as Headdriven Phrase Structure Grammar (Sag et al. 2003) and Lexical-Functional Grammar (Dalrymple 2001), attention has been paid to the issue of how a competence model is transparently embedded within a performance model (Sag \& Wasow 2011). Dynamic Syntax (DS) (Cann et al. 2005, Kempson et al. 2001, 2011) is yet another approach to linguistic enquiry that seeks to establish a performance-compatible competence model. In DS, competence is viewed as a set of constraints on language use, more specifically, a set of constraints on building up a structured interpretation through incremental, word-by-word parsing (see, e.g., Gregoromichelaki et al. 2011, Howes 2012 for the DS modelling of language production with the same machinery). The mapping from a string of words to an interpretation is direct in that no independent level of syntactic structure is posited. The core notion of DS - incremental growth of 
interpretation - has been demonstrated against a variety of structural phenomena and across a broad empirical base of languages. ${ }^{1}$

The present article argues for the significance of incrementality in syntactic theory by examining cleft constructions in two genetically/geographically unrelated languages: Japanese and Rangi (a Bantu language spoken in Tanzania). There are reasons to choose these as our target languages. Japanese has been studied extensively in theoretical syntax, and there is a wealth of past studies on Japanese clefts (Hiraiwa \& Ishihara 2012, Kizu 2005, Author 2013). Japanese is therefore well-suited to test the adequacy of our account, embedding our findings within past works. Moreover, Japanese poses an illuminating puzzle for modelling incremental parsing since the verb - which is assumed to be a core element in terms of structure building - always comes clause-finally. Yet, the parser appears to start to process a clause even before the verb is encountered (Kamide 2006, Kiaer 2014); see also Kahraman et al. (2011) for Japanese cleft data. We also provide data on the case-marking of multiple foci in Japanese clefts, reinforcing Author's (2013) observations. Rangi remains underdescribed, and in particular, no detailed examination of clefts in the language has previously been offered. Our findings therefore contribute to the description of the language, as well as extending the empirical coverage of the DS modelling of clefts cross-linguistically. Rangi and Japanese clefts differ in a number of respects. For example, while clefts in both languages involve the sequence of a copula and a focus item, the linear order differs: in Japanese the ordering is focus-copula whilst in Rangi it is copula-focus. The positioning of the cleft cluster also differs: whilst the cluster appears sentence-finally in Japanese, it is sentence-initial in Rangi. These differences set a challenge particularly for surface-oriented grammars like DS, which defines a set of constraints on building licit structures reflecting the parse of a surface string. ${ }^{2}$ Another crucial difference that will be addressed is that Japanese clefts allow multiple foci whilst these are barred in Rangi. The claim is that this difference reflects the way a structure is established, with underspecifications being gradually resolved. As such, Japanese and Rangi clefts pose problems for both surface-oriented grammars and syntactic research in general.

Section 2 sets out the data on Japanese and Rangi clefts. Section 3 introduces the DS framework, and Section 4 develops a formal account which predicts a number of properties of Japanese and Rangi clefts, including their cross-language parallelisms and differences. Section 5 constitutes a summary of the main results, highlighting implications for a dynamic typological model of clefts.

\footnotetext{
${ }^{1}$ This growing coverage includes work on a wide range of languages including Medieval Spanish (Bouzouita 2011), Latin (Kempson et al. 2013), dialects of Modern Greek (Chatzikyriakidis 2010), Korean (Kiaer 2014), Japanese (Author 2013), and Chinese (Yicheng 2011), as well as languages in the Bantu family such as Swahili (Marten 2002, Cann et al. 2005), siSwati (Kempson et al. 2011), and Rangi (Author 2012).

${ }^{2}$ As noted by a reviewer, these differences may be generalised in terms of the head-parameter in mainstream generative grammar. As a parsing-oriented framework, however, DS does not employ such parametric devices, and lexically-specified input is considered responsible for whether a transition from a particular tree state to another state is licit. Still, it is true that there is a tendency that head-initial/-final orders are consistent across constructions in languages, and it must be seen in future research how this consistency (together with its exceptions) is predicted within DS.
} 
This is the accepted version of a final article which will be published by Elsevier in Language Sciences. Final published version available at: 10.1016/j.langsci.2016.03.003

Accepted Version downloaded from SOAS Research Online: http://eprints.soas.ac.uk/22203/

\section{The Cleft Data}

\subsection{Japanese Clefts}

Japanese is strictly verb-final, with a basic S-O-V word order. In (1), the subject NP is marked with the nominative case particle $g a$ and the object NP hosts the accusative case particle $o$.

\section{(1) Ruth-ga ie-de ringo-o tabe-ta \\ R-NOM house-in apple-ACC eat-PAST \\ 'Ruth ate apples in the house'}

The order of the constituents in the clause is free as long as the verb appears clausefinally. For instance, the ordering shown in (2) is also permissible with the same meaning (in terms of truth conditions) as conveyed by (1).

\section{(2) ie-de ringo-o Ruth-ga tabe-ta \\ house-in apple-ACC R-NOM eat-PAST \\ 'Ruth ate apples in the house.'}

Japanese clefts are formed with three grammatical elements: the particle $n o,{ }^{3}$ the topic marker $w a$, and the copula $d a$. The pre-no clause (called the "presupposition clause" (Kizu 2005)) establishes the background. This clause involves a gap, to be associated with a focus. A "gap" here is construed theory-neutrally (see Section 4.1.1 for discussion). The presupposition clause is nominalised by no and topicalised by wa. A focus element is then presented, and the string is closed with the copula $d a$.

(3) [Ruth-ga tabe-ta no]-wa ringo(-o) da

[R-NOM eat-PAST NO]-TOP apple(-ACC) COP

'It is apples that Ruth ate.'

The focus ringo 'apple' is optionally case-marked. For some speakers, clefts with an accusative $o$-marked focus are degraded (Hiraiwa \& Ishihara 2012), but the present article sets aside this cross-speaker variation. (The nominative ga-marking of a focus often lessens acceptability more, but such examples are attested spontaneously; see also footnote 19).

There are restrictions on the type of element that may be in focus in a cleft. First, the focus ringo 'apple' in (3) is analysed to be of type e within DS. ${ }^{4}$ Second, as exemplified in (4)-(5), a focus position may be inhabited by the postposition phrase ie-de 'in the house' or the adverb phrase ikioiyoku 'vigorously.'

\footnotetext{
${ }^{3}$ No has been analysed diversely as a pre-nominal marker (Kitagawa \& Ross 1982), a pronominal (Hoji 1990), a complementiser (Kizu 2005), etc. In Section 4.1, no is regarded as a nominaliser; see Author (2013: Ch.4) for its applications to the pronominal no and the complementiser no. ${ }^{4}$ Unlike the usual treatment of a common noun as a type-<e, $t>$ element (Heim \& Kratzer 1998) and of a quantified element as a type- $<<e, t>, t>$ element (Montague 1973), DS utilises the epsilon calculus where ringo is mapped onto a type-e epsilon term, though the epsilon notation is avoided in the present article in the interests of brevity.
} 
This is the accepted version of a final article which will be published by Elsevier in Language Sciences. Final published version available at: 10.1016/j.langsci.2016.03.003

Accepted Version downloaded from SOAS Research Online: http://eprints.soas.ac.uk/22203/

[Ruth-ga ringo-o tabe-ta no]-wa ie(-de) da [R-NOM apple-ACC eat-PAST NO]-TOP house(-in) COP 'It is in the house that Ruth ate apples.'

(5) [Ruth-ga ringo-o tabe-ta no]-wa ikioiyoku da [R-NOM apple-ACC eat-PAST NO]-TOP vigorously COP 'It is vigorously that Ruth ate apples.'

Marten (2002) holds that adjuncts like ie-de 'in the house' and ikioiyoku 'vigorously' are of type e. ${ }^{5}$ Finally, it is not possible for predicates to occupy this focus position, as shown in (6). In order for a predicate to be focussed, it must be nominalised as in (7).

* [Ruth-ga shi-ta no]-wa ringo-o tabe-ta da

[R-NOM do-PAST NO]-TOP apple-ACC eat-PAST COP

Int. 'It is to eat apples that Ruth did.'

(7) [Ruth-ga shi-ta no]-wa [ringo-o tabe-ru koto] da

[R-NOM do-PAST NO]-TOP [apple-ACC eat-INF KOTO] COP

Lit. 'It is to eat apples that Ruth did.'

In (7), the focus is of type-e because it is nominalised by koto. So, a generalisation seems to be that only type-e elements (as construed in DS) may be licensed at a focus position in Japanese clefts. This contrasts with languages like Haitian (Harbour 2008), where "predicate clefts" are licensed.

Another interesting property of Japanese clefts concerns multiple foci. In (8), there are two foci: ie-de 'in the house' and ringo-o 'apple.' Author (2013) observes that a case particle may be dropped from the final focus ringo 'apple' but not the nonfinal focus ie.

(8) [Ruth-ga tabe-ta no]-wa ie-de ringo(-o) da

[R-NOM eat-PAST NO]-TOP house-in apple(-ACC) COP

Lit. 'It is in the house and it is apples that Ruth ate.'

It is possible to have more than two foci, as in (9). In such instances, it is again only possible for the particle to be dropped from the final focus ringo.

(9) [tabe-ta no]-wa Ruth-ga ie-de ringo(-o) da

[eat-PAST NO]-TOP R-NOM house-in apple(-ACC) COP

Lit. 'It is Ruth, it is in her house, and it is apples that ate.'

However, the above case-marking pattern is challenged by the examples below (provided by a reviewer). If $d e$ 'in' is left out, these strings seem totally unacceptable. This may suggest particle-drop is possible only with the accusative case particle $o$.

\footnotetext{
${ }^{5}$ Marten's analysis stems from the concept of verbal type underspecification based on a number of empirical data which seem to blur the argument/adjunct distinction (e.g. agreement in Chamoro, case assignment in Finish), with the proposal being applied to a range of Swahili applicative verbs. Our adoption of Marten's account is for simplicity; an alternative (which complicates our analysis but fits in the standard analysis of adjuncts) is to introduce a type-e situation term (cf., Davidson 1967), as suggested in the DS literature (Gregoromichelaki 2006).
} 
This is the accepted version of a final article which will be published by Elsevier in Language Sciences. Final published version available at: 10.1016/j.langsci.2016.03.003

Accepted Version downloaded from SOAS Research Online: http://eprints.soas.ac.uk/22203/

(10) $[$ Ruth-ga tabe-ta no]-wa ringo-o ie*(-de) da [R-NOM eat-PAST NO]-TOP apple(-ACC) house(-in) COP Lit. 'It is apples and it is in her house that Ruth ate.'

(11) [ringo-o tabe-ta no]-wa Ruth-ga ie*(-de) da [apple-ACC eat-PAST NO]-TOP R-NOM house(-in) COP Lit. 'It is Ruth and it is in her house that ate apples.'

Acceptability, however, may be improved in some contexts. Consider (12), where the cleft string (10) is contained in B's utterance (rashiiyo is treated as a "hearsay" final particle). The context is as follows: someone saw Ruth holding an empty lunch box after a meeting, and told A about it. A was surprised, and tells it to B. But B attended the meeting, and knows that Ruth held her friend's lunch box while the friend was in a toilette. B also knows that Ruth took only an apple for lunch at home since she overslept. B thus wants to correct A's recognition of Ruth, stressing that she is a thoughtful person who would not take lunch during a formal meeting.
A: Ruth-ga bentou-o
daigaku-de
kaigi-chuuni
tabe-ta-rashiiyo
R-NOM lunch.box-ACC university-in meeting-during eat-PAST-FP
'I heard that Ruth ate a lunch box during a meeting at a university.'
B: iya iya nani-o i-tteru-no
no no what-ACC say-PROG-Q
[Ruth-ga tabe-ta no]-wa ringo-o ie??(-de) da-yo
[R-NOM eat-PAST NO]-TOP apple-ACC house(-in) COP-FP
'No, it is not true. It is an apple and it is in her house that Ruth ate!'

The cleft in B's utterance is still not quite acceptable (in fact, it is hardly acceptable for a reviewer), but for the author, the following pattern seems the case with regard to the acceptability pattern of the focus cluster in (12)b.
(13) a. ringo-o ie-de
b. ?? ringo-o ie
c. * ringo ie-de
d. *ringo ie

In (12)b, the cluster (13)b is still degraded, but it seems somehow better than (13)c-d, which are fully unacceptable. That is, if the case particle $o$ is dropped off the non-final focus ringo, the string is completely unacceptable no matter how it is contextualised. In addition, (12)b with the cluster (13)b seems (albeit slightly) more acceptable than the decontextualised one (10). We therefore assume that clefts with particle-drop on the final focus like (10)-(11) are not ungrammatical.

Moreover, even for those who still feel that acceptability is not improved in (12), there are reasonably acceptable instances of clefts where a particle other than $o$ may be dropped at the final focus (and only at the final focus).

(14) [Ruth-ga Tom-to au no]-wa niji*(-ni) sono-ekimae(-de) da [R-NOM T-and meet NO]-TOP 2-at that-station.front(-at) COP Lit. 'It is at 2 and it is in front of that station that Ruth will meet up with Tom.' 
This is the accepted version of a final article which will be published by Elsevier in Language Sciences. Final published version available at: 10.1016/j.langsci.2016.03.003

Accepted Version downloaded from SOAS Research Online: http://eprints.soas.ac.uk/22203/

The particle $d e$ 'at' attached to the final focus may be dropped, but the particle $n i$ 'at' attached to the non-final focus cannot be dropped in any context.

The present discussion raises the question of why the de-stripped focus (10)-(11) is more degraded than the $o$-stripped focus (9). Though a comprehensive analysis needs to answer this question, this article sets it aside (assuming that such degraded clefts are not ungrammatical). ${ }^{6}$ Then, our multiple foci data are summed up as (15).

(15) In Japanese clefts, all foci but the final focus must be case-marked. That is, the case-drop of the final focus could yield a grammatical string in context, and the case-drop of a non-final focus never yields a grammatical string in any context.

According to (15), our account will be falsified by any instance of clefts where a particle is dropped from a non-final focus. Still, it will not be immediately falsified by an instance of clefts where a particle cannot be dropped at the final focus in context (although the question raised immediately above (15) remains).

In the remainder of this subsection, we shall discuss (putative) counterexamples to (15). Consider (16), where all of the foci ringo 'apple,' orenji 'orange,' and banana 'banana' appear without case-marking.

$$
\begin{aligned}
& \text { Tom-ga tabe-ta no]-wa ringo orenji banana da } \\
& \text { [T-NOM eat-PAST NO]-TOP apple orange banana COP } \\
& \text { 'It is apples, oranges, and bananas that Tom ate.' }
\end{aligned}
$$

In (16), however, the three foci serve as an object of the embedded verb tabe- 'eat.' That is, the foci cluster may be seen as a coordinated nominal complex, as in (17).
(17) [Tom-ga tabe-ta no]-wa [ringo-to orenji-to banana] da [T-NOM eat-PAST NO]-TOP [apple-and orange-and banana] COP 'It is apples, oranges, and bananas that Tom ate.'

The coordinated status of successive NPs at a focus position can also be seen in (18).

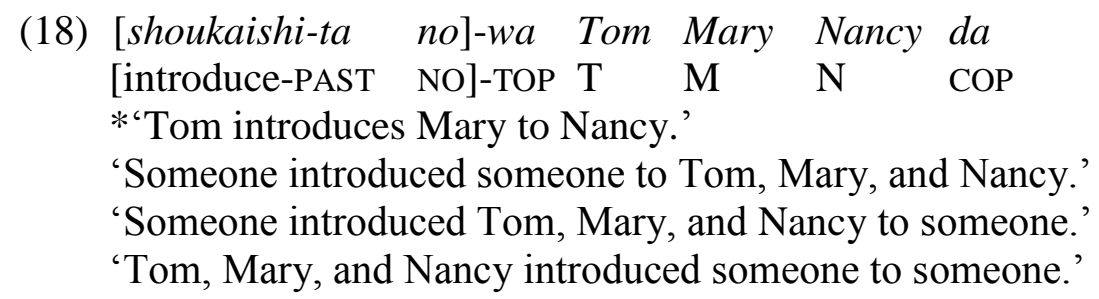

Shoukaishi- 'introduce' selects three NPs denoting humans. Given that Tom, Mary, and Nancy all denote human individuals, we may expect they could have different grammatical functions, like 'Tom (Subject) introduced Mary (Direct Object) to Nancy

\footnotetext{
${ }^{6}$ A reviewer notes that if the cluster in (14) is swapped as in sono-ekimae-de niji-ni 'in front of that station, at 2,' $n i$ cannot be dropped, whilst for the author this is acceptable. (This variation is consistent with (15) as de in this swapped cluster cannot be dropped for both the reviewer and the author.) The reviewer also suggests that the nominative particle $g a$ seems never to be dropped at the final focus. A systematic study of cleft acceptability with various types of particle/postposition (as well as cross-speaker variation) would require a large-scale corpus/questionnaire survey and remains as an issue for future work.
} 
This is the accepted version of a final article which will be published by Elsevier in Language Sciences. Final published version available at: 10.1016/j.langsci.2016.03.003

Accepted Version downloaded from SOAS Research Online: http://eprints.soas.ac.uk/22203/

(Indirect Object).' But this reading is impossible, as marked with * in (18). The string only receives the three readings provided in (18), where the three NPs in total have a single grammatical function. In short, if multiple caseless NPs are placed at a focus position and if the string is acceptable, these NPs must be coordinated so as to receive a single grammatical function.

Let us turn to the case-marking pattern of (16). In the coordinated foci cluster, it is impossible to case-mark non-final foci. For instance, the first focus ringo cannot be case-marked, as shown in (19).

(19) *[Tom-ga tabe-ta no]-wa ringo-o orenji banana da. [T-NOM eat-PAST NO]-TOP apple-ACC orange banana COP Int. 'It is apples, oranges, and bananas that Tom ate.'

Similarly, the following case-marking patterns all result in unacceptability: (i) only orenji is case-marked, (ii) only ringo and orenji are case-marked, (iii) only ringo and banana are case-marked, (iv) only orenji and banana are case-marked, and (v) all NPs are case-marked.

There is a single acceptable pattern: only the final focus banana is case-marked. The string (20) may not be readily acceptable, but there is a sharp contrast between (20) and (19) (and the other five case-marking patterns mentioned above).

\section{(20) ?[Tom-ga tabe-ta no]-wa ringo orenji banana-o da [T-NOM eat-PAST NO]-TOP apple orange banana-ACC COP 'It is apples, oranges, and bananas that Tom ate.'}

This case-marking pattern is compatible with our contention that the foci constitute an integrated element, provided that a case particle may be attached to the integrated element as a whole but not part of the element. Therefore, the case-marking patterns revealed in (16)-(20) do not contradict with (15). ${ }^{7}$

The picture arising from the above discussion is summarised in (21). In the next subsection, we shall see that the data on Rangi clefts differ from the generalisation developed for Japanese, constituting a cross-language cleft problem.

\footnotetext{
${ }^{7}$ The coordination data have been presented to confirm (15), and a full account of such data is pending. In DS, coordination is dealt with by means of the "LINK" device (Cann et al. 2005), which is in principle applicable to the above data. (Further, a plural operator would be in order to denote a group entity à la Link (1983); see Author (2013: 308-9).) Notably, as the parse of a case particle at a "LINKed" node in such context aborts a tree-update (Author 2013), the case-marking patterns in (16)-(20) are generally expected. Still, a reviewer notes that in coordinated foci, each non-final focus may be case-marked if soshite 'and' is placed before the final focus, as in (i). This may be captured by the entry of soshite, but the detail of analysis is left for future research.

(i) [Tom-ga tabe-ta no]-wa ringo-o orenji-o soshite banana(-o) da [T-NOM eat-PAST NO]-TOP apple-ACC orange-ACC and banana(-ACC) COP 'It is apples, oranges, and bananas that Tom ate.'
} 
This is the accepted version of a final article which will be published by Elsevier in Language Sciences. Final published version available at: 10.1016/j.langsci.2016.03.003

Accepted Version downloaded from SOAS Research Online: http://eprints.soas.ac.uk/22203/

(21) Focus elements in Japanese clefts

a. If multiple foci have a single grammatical function, they are coordinated foci with a joint focal interpretation, and all foci but the final one must not be casemarked.

b. If multiple foci have multiple grammatical functions, all foci but the final one must be case-marked. That is, case-drop is potentially possible at the final focus, while it is never possible at the non-final focus (see (15) for clarification).

\subsection{Rangi Clefts}

Rangi is a Bantu language spoken in central Tanzania. Rangi has morphologically complex verbs and a basic S-V-O word-order, which allows for some flexibility of constituent order. Lexical subjects and objects are co-indexed on the verb by an extensive system of agreement. Rangi (like Japanese) exhibits pro-drop, and in the appropriate context, overt subject and object NPs can be omitted, with the inflected verb form functioning as a complete utterance.

A simple verbal construction employs a single verb which is inflected for tense (and optionally aspect), with subject agreement taking the form of a prefix on the verb (Dunham 2004, Stegen 2001, 2006). This can be seen in (22), where the subject NP nitni 'I' appears clause-initially, and the verb stem -tereka 'cook' is prefixed by the progressive marker íyó- and the first person singular subject marker $n$-. The object NP chákurya 'food' appears after the verb. ${ }^{8}$
nit́nì n-íyó-térek-a
chá-kurya
$1^{\text {st }}$.SG.PP SM. $1^{\text {st }}$.SG-PRES.PROG-cook-FV 7-food
'I am cooking food.'

In addition to simple verb structures, Rangi exhibits compound constructions in which an auxiliary form is used alongside the main verb. This can be seen in (23), where the auxiliary -ija is used with the main verb -suka 'plait' and the appropriate inflectional morphology to encode a distant past habitual interpretation.

$\begin{array}{llll}\text { (23) Ana } & a \text {-íja } & a ́ \text {-súk-áa } & n d i h i \\ \text { A } & \text { SM.1-AUX } & \text { SM.1.PAST.2-plait-PAST.HAB 10.rope }\end{array}$

'Anna used to plait rope.'

Clefts in Bantu languages are commonly formed through a copula that appears clause-initially and results in a focal reading on the post-copula element. The use of clefts in Bantu languages is widespread, and Watters (2000: 216) notes that the cleft construction is probably the most widespread strategy to mark new information focus amongst African languages. Clefts in Rangi employ the copula $n \dot{t}$ which is positioned in front of the verbal complex resulting in the fronted expression receiving a focus interpretation. ${ }^{9}$ This focus cluster is followed by a clause with a gap (to be associated

\footnotetext{
${ }^{8}$ Rangi has a 7-vowel system. We follow Stegen (2001) and Author (2012) under which the vowels $\mho$ and I are represented orthographically as $t$ and $i$ respectively.

${ }^{9}$ We assume that only type-e elements are licensed as foci in Rangi clefts. Whilst our corpus does not include examples of predicate focus, even if a verbal element appeared as the focus of a cleft, it would appear as an infinitival form since this is the only way to encode predicate focus. The Bantu infinitive has long been noted to exhibit both verbal and nominal properties (Creissels \&
} 
This is the accepted version of a final article which will be published by Elsevier in Language Sciences. Final published version available at: 10.1016/j.langsci.2016.03.003

Accepted Version downloaded from SOAS Research Online: http://eprints.soas.ac.uk/22203/

with a focus). This can be seen in (24), where the copula $n \dot{t}$ introduces the focus $n a$ Dodoma 'to Dodoma.' Similarly, in (25), the copula $n \dot{t}$ is placed before a nominal phrase, resulting in a contrastive focus on mboha já masaambi 'cassava leaves.'

(24) né na Dodoma n-íyó-dom-a

COP PREP D $\quad$ SM. $1^{\text {st }}$.SG-PROG-go-FV

'It is to Dodoma that I am going.'

(25) ni mboha j-á masaambi na-térek-a

COP 10.vegetable 10-of cassava.leaves SM. ${ }^{\text {st }}$.SG.PRES-cook-FV

'It is cassava leaves that I am cooking.'

Rangi clefts exhibit two surface differences from those found in Japanese. Firstly, the focussed item and copula appear clause-initially in Rangi clefts, whilst appearing clause-finally in Japanese. Secondly, the ordering of this pair also differs: in Rangi clefts, the order is copula-focus while in Japanese clefts, the order is focus-copula. These differences challenge surface-oriented grammars like DS, raising the questions of why the parse of a string in a certain order leads to a licit structure in one language (but not the other language), and why the parse of a string in another order leads to a licit structure in one language (but not the other language).

The $n \dot{t}$ cleft can also be used with a complex verbal construction. The general future tense in Rangi is formed with an uninflected, infinitival verb form and the auxiliary $-r \dot{t}(26)$.

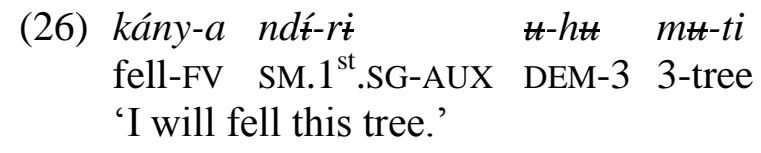

The post-verbal placement of the auxiliary in the future tense is unusual from both a typological and comparative perspective (see Author (2012) for details). Of particular interest for our current purposes, however, is that the formation of a cleft in this future tense construction results in a word-order change, yielding pre-verbal placement of the auxiliary (27). An attempt at post-verbal auxiliary placement in a cleft leads to ungrammaticality (28). ${ }^{10}$

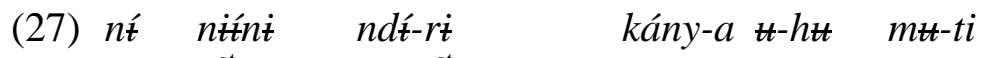 COP $1^{\text {st }}$.SG.PP SM. $1^{\text {st }}$.SG-AUX cut-FV DEM-3 3-tree 'It is me that will fell this tree.'

\footnotetext{
Godard 2005, Visser 1989, Author 2012). As such, it would still be possible to consider such a "verbal" element at a focus position in a cleft to be of type e.

${ }^{10}$ As suggested by a reviewer, such behaviour exhibits parallels with the verb-second effect in a language like German in which the auxiliary follows the verb in embedded clauses, unless topicalisation has occurred in which case the auxiliary must appear before the verb. A DS analysis of such constructions may also be provided in terms of the Unique-Unfixed Node Constraint (see (69)). In fact, this constraint plays a role in a number of other phenomena such as clitic placement and clitic clustering phenomena in dialects of Modern Greek (Chatzikyriakidis 2010) and Medieval Spanish (Bouzouita \& Chatzikyriakidis 2009).
} 
This is the accepted version of a final article which will be published by Elsevier in Language Sciences. Final published version available at: 10.1016/j.langsci.2016.03.003

Accepted Version downloaded from SOAS Research Online: http://eprints.soas.ac.uk/22203/
(28) *né níní kány-a ndt́-rí $\boldsymbol{t}$-ht $m \boldsymbol{t}$-ti COP $1^{\text {st }}$.SG.PP cut-FV SM. $1^{\text {st }}$.SG-AUX DEM-3 3-tree Int. 'It is me that will fell this tree.'

A striking contrast with Japanese is found in multiple foci. Unlike Japanese, it is not possible for more than one expression to be focused in Rangi clefts. For instance, in (29), there is no way to retrieve an interpretation with two foci; rather, the string is rendered ungrammatical.
(29) *ní níńt

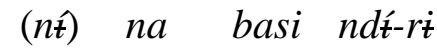
dóm-a na Dodoma
COP PP. $1^{\text {st }}$.SG
(COP) PREP 9.
9.bus S
$1^{\text {st }}$.SG-AUX go-FV PREP D
Int. 'It is me and it is by bus that I am going to Dodoma.'

It is still possible to place multiple elements at a focus position, but in such cases, the coordinator $n a$ 'and, with' is present, and the multiple elements must have a single grammatical function such as Object in (30), with the coordinated elements wari na mahalga 'ugali and beans, ${ }^{11}$ receiving a joint focal interpretation.
(30) $n \dot{t}$ wari *(na) ma-halaga tú-rí kttry-a
COP 14-ugali (CONN) 6-beans SM. $1^{\text {st }}$.PL INF-eat-FV
'It is ugali and beans that we will eat.'

It is also noted that unlike Japanese clefts, the cleft string is ungrammatical in Rangi if the coordinator $n a$ is dropped. The ungrammaticality of (30) without $n a$ is due to the fact that in general (i.e., non-cleft environments), multiple NPs cannot be combined without $n a$ in Rangi. ${ }^{12}$
(31) ktt-ry-a tú-rí wari *(na) ma-halaga
INF-eat-FV SM. $1^{\text {st }}$.PL 14-ugali (CONN) 6-beans
'We will eat ugali and beans.'

A similar situation is seen in (32), where the entire phrase Dodoma na Kondoa may receive focus as a coordinated phrase. Again, in order for the non-cleft counterpart of such an example to be grammatical, the coordinator $n a$ must be present as in (33).
(32) $n$
ni na Dodoma *(na) Kondoa n-íyó-dom-a

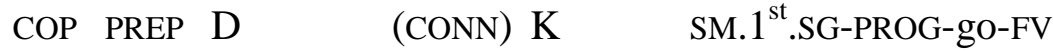
'It is to Dodoma and Kondoa that I am going.'
(33) n-íyó-dom-a na Dodoma *(na) Kondoa
SM. $1^{\text {st }}$.SG-PROG-go-FV PREP D (CONN) K
'I am going to Dodoma and Kondoa.'

\footnotetext{
${ }^{11}$ Ugali is a stiff maize meal porridge eaten throughout East Africa.

${ }^{12}$ When more than two NPs are combined, the coordinator $n a$ is optional in the focus cluster in clefts. (There is a tendency that $n a$ occurs between the last two items in careful speech.) Even in this case, the obtained interpretation is a joint focus interpretation (where the coordinated foci in total have a single grammatical function). Further, a parallelism finds itself with regard to the optionality of $n a$ in the non-cleft environment; that is, $n a$ is also optional when more than two NPs are coordinated in a non-cleft string.
} 
This is the accepted version of a final article which will be published by Elsevier in Language Sciences. Final published version available at: 10.1016/j.langsci.2016.03.003

Accepted Version downloaded from SOAS Research Online: http://eprints.soas.ac.uk/22203/

The Rangi data examined above are condensed into the generalisation in (34). This can be contrasted with the generalisation about Japanese clefts (21).

(34) Focus elements in Rangi clefts

a. Multiple elements can be combined together when the coordinator $n a$ is present. These focus elements receive a single grammatical function with a joint focal interpretation.

b. If multiple elements at a focus position have distinct grammatical functions, a cleft is always ungrammatical.

\subsection{Summary}

This section has shed light on several grammatical properties of Japanese and Rangi clefts. Parallelisms are detected in information structure terms. In both languages, a cleft string evokes the presentation of background information and the provision of focal information which is assessed against this background. In both languages, the background is conveyed by a clause with a gap, and a focus position is marked by the presence of a copula: $d a$ in Japanese and $n t$ in Rangi. The nature of the focussed element is also common across the two languages: only type-e items (as construed with the DS assumptions) are licensed in the focus position.

What makes the two languages a promising test case for cross-linguistic enquiry into clefts is that they also display a range of differences. Firstly, the order of a focus and a copula is the opposite in the two languages: focus-copula order in Japanese vs. copula-focus order in Rangi. Secondly, the sequence involving the focus and the copula itself is positioned differently, appearing clause-finally in Japanese and clauseinitially in Rangi. These differences raise an immediate puzzle for any incremental analysis of clefts based on left-to-right parsing. Thirdly, a range of data pertaining to multiple foci raises cross-linguistic questions. As stated in (21) and (34), multiple foci are possible only in Japanese clefts, although there are certain restrictions on the casemarking of foci: unless foci receive a coordination reading, the case-marking of foci is obligatory on all except the final focus. Multiple foci are barred in Rangi clefts, but multiple items can be marked for focus if they receive a single grammatical function.

The similarities and differences manifested by Japanese and Rangi clefts give rise to the problem of how to model the incremental parsing of a cleft string online (Kahraman et al. 2011). This consideration imposes another restriction on possible accounts; the cleft problems cannot simply be solved syntactically, but it must also be shown that an account is realistically embedded within a performance model whereby a cleft string is interpreted progressively. It should also not go unnoticed that the data surveyed are valuable not only theoretically but also from a descriptive perspective. The data on Japanese clefts have been widely noticed, but this article reinforces the multiple foci data reported in Author (2013). Rangi clefts have not previously been described and are only partially examined in Author (2012); the account provided here therefore also enhances the description of this area of Rangi grammar.

Now that the data to be examined are in place, the next section provides the theoretical scaffolding against which these data are given a dynamic account. 


\section{Dynamic Syntax (DS)}

Like other generative theories, Dynamic Syntax explicates linguistic competence, but the DS concept of competence is a set of (i) procedures which gradually update an interpretation and (ii) constraints on this interpretation update (Cann et al. 2005, Kempson et al. 2001, 2011). Against the backdrop of these procedures/constraints, the parser takes a string word-by-word, and incrementally updates a semantic structure without any independent level of syntactic representation. In DS, the parser is not a supplementary device postulated separately from a grammar; rather, the parser itself is a core syntactic device, where "syntactic" means that the device is equipped with a set of procedures/constraints used to construct a semantic representation.

DS semantic structure and its gradual update are expressed using binary trees. Suppose we parse Tom runs (ignoring tense). The tree-update proceeds as follows:

Growth of a semantic tree

(a) root node

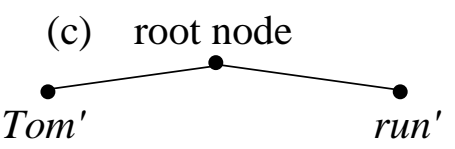

(b)
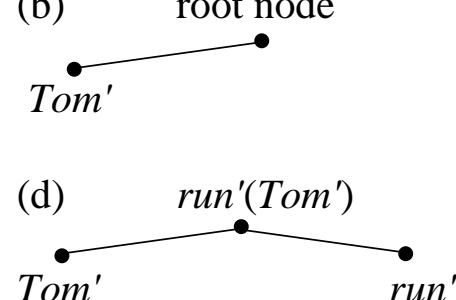

First, (35)a sets the starting point for a parse. At this stage, there is only a "root" node (i.e., node at the highest position in a tree). Second, (35)b refers to the stage where Tom has been parsed. At this stage, an argument node has been created and annotated with Tom'. (Tom' is the semantic content of the expression Tom.) Third, (35)c refers to the stage where run has been parsed. At this stage, a functor node has been created and annotated with run', or more precisely, the content of run. Finally, (35)d refers to the final stage, where the content $\operatorname{run}^{\prime}\left(\mathrm{Tom}^{\prime}\right)$ at the root node is calculated based on the contents run' and Tom' at the daughter nodes. ${ }^{13}$

The informal exegesis above is substantiated below. Section 3.1 introduces the basic machinery of Dynamic Syntax exemplified through Japanese, and Section 3.2 enriches it with the LINK device, drawing on examples from Rangi.

\subsection{The Basic Tools}

The DS parser builds a semantic tree which represents an interpretation of a string parsed. DS semantic trees are binary-branching; by convention, arguments are placed at the left nodes and predicates are placed at the right nodes. For example, the parse of Tom runs yields the tree (36), ignoring tense/aspect (see Cann 2011). This is the detailed version of the informal tree (35)d.

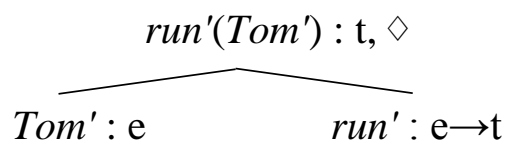

${ }^{13}$ This semantic composition is generally called "functional application." In (35), run' is a functor which takes the content Tom' as argument and returns the content run'(Tom') as value. run'(Tom') expresses the proposition 'Tom runs.' 
This is the accepted version of a final article which will be published by Elsevier in Language Sciences. Final published version available at: 10.1016/j.langsci.2016.03.003

Accepted Version downloaded from SOAS Research Online: http://eprints.soas.ac.uk/22203/

Each node is annotated with two types of information: semantic content and semantic type. This pair is notated as in Tom': e, where Tom' is a content and e is a type of the content. There are two basic types: "e" and "t." The type "e" indicates that a content is an entity (e.g., human individual), while the type " $t$ " indicates that a content is a truthevaluable statement (i.e., proposition). There are also complex types. For instance, the type " $\mathrm{e} \rightarrow \mathrm{t}$ " indicates that some content is a functor that takes a type-e content and returns a type-t content. Another symbol - the "pointer" $\diamond-$ can also be seen in example (36). Since a DS tree is gradually updated, the pointer $\diamond$ indicates the node under development at any given stage in the parse.

The tree grows incrementally as a parse proceeds. The initial stage (35)a is more formally known as the AXIOM.

$$
\frac{\text { Initial state }}{? \mathrm{t}, \diamond} \text { (the AXIOM) }
$$

The root node is annotated with ?t, a requirement that the node will be annotated with a type-t content (i.e., propositional content like $\operatorname{run}^{\prime}\left(\operatorname{Tom}^{\prime}\right)$ ).

There is subsequently a sequence of intermediate states, as illustrated in (35)b-c. The tree (35)c, for instance, is expressed more richly as (38).

$$
\frac{\text { An intermediate state (corresponding to }(35) \mathrm{c} \text { ) }}{? \mathrm{t}, \diamond}
$$

At this stage, the requirement ?t at the root node has not been satisfied yet because the type-t content is still absent.

The final stage (35)d is delineated as (39) $(=(36))$. In this tree state, the type-t, propositional content $\mathrm{run}^{\prime}\left(\mathrm{Tom}^{\prime}\right)$ appears, and thus the requirement for a type-t content (indicated by ?t) has been met.

$$
\underset{\text { Tom }^{\prime}: \mathrm{e} \quad \operatorname{run}^{\prime}\left(\text { Tom }^{\prime}\right): \mathrm{t}, \diamond}{\text { run }^{\prime}: \mathrm{e} \rightarrow \mathrm{t}}
$$

This tree state is said to be "well-formed" in that all requirements (such as ?t in (38)) have been satisfied and removed.

A tree is gradually updated by a combination of (i) lexical, (ii) general, and (iii) pragmatic actions. Lexical actions are specified in each expression. For example, the lexical item Tom encodes the action to derive the tree-update shown in (40).

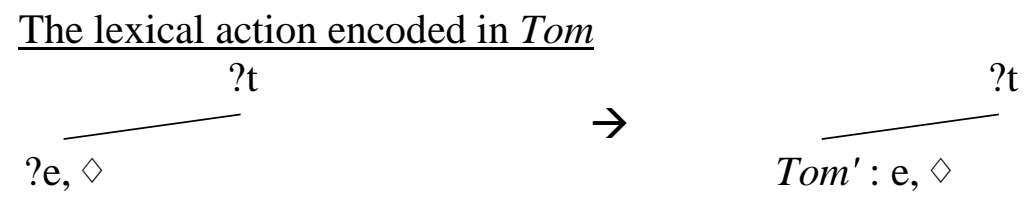

The node under development (indicated by the pointer $\diamond$ ) is annotated with ?e, which requires that this node will be annotated with some type-e content (i.e., entity-type 
This is the accepted version of a final article which will be published by Elsevier in Language Sciences. Final published version available at: 10.1016/j.langsci.2016.03.003

Accepted Version downloaded from SOAS Research Online: http://eprints.soas.ac.uk/22203/

content). The parse of Tom, then, provides the content Tom' and the semantic type of the content, namely e (i.e., entity-type).

General actions are linguistic actions that are not encoded in lexical items. As an example, functional application (see footnote 13) is formulated as ELIMINATION.

(41) The general action ELIMINATION

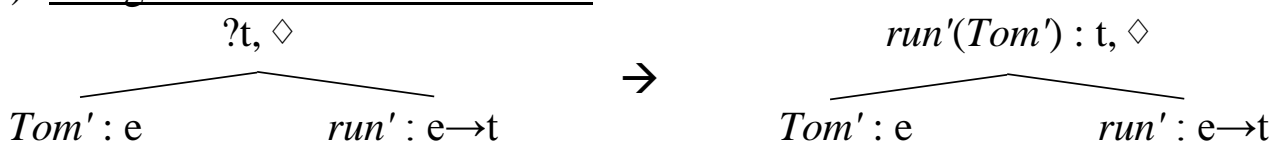

Finally, pragmatic actions are contextually driven. For instance, SUBSTITUTION can give a contextually salient value to an anaphoric item. Suppose we parse He runs. The parse of he posits a metavariable $\mathrm{U}$, a place-holding device to be saturated.

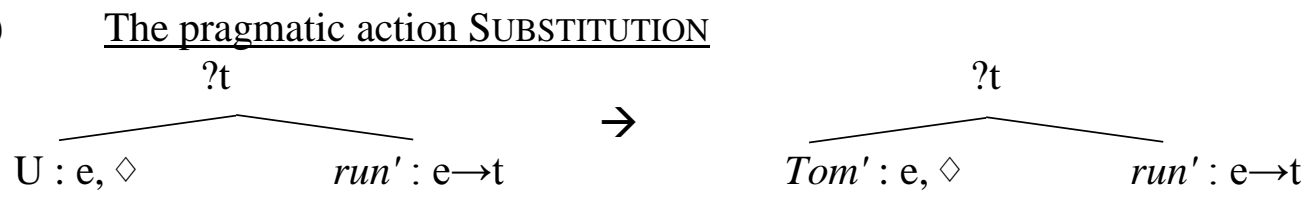

Setting aside bound-variable cases, $\mathrm{U}$ is contextually saturated, and this is formalised as Substitution. That is, the parser updates $U$ with an appropriate value such as Tom'.

In our treatment of Japanese and Rangi clefts (see Section 4), the analysis relies on the DS insight that languages differ in the balance of which portions of actions are realised as lexical actions or non-lexical actions (Cann et al. 2005).

Before illustrating the application of the framework, the general action of LOCAL *ADJUNCTION also needs to be introduced. This action is particularly significant for verb-final languages such as Japanese. In Japanese, the verb, which is presumed to encode core instructions for structure building, appears clause-finally in terms of left-to-right parsing. It may therefore seem as though no substantive structure building occurs until the verb is parsed (Pritchett 1992), but a growing amount of psycholinguistic evidence indicates otherwise (Kamide 2006). DS models this "delay" in the update process by defining an "unfixed" node, a node whose position in a tree is initially uncertain and will only be resolved at a later point. Such an unfixed node is introduced by LOCAL *ADJUNCTION (43).

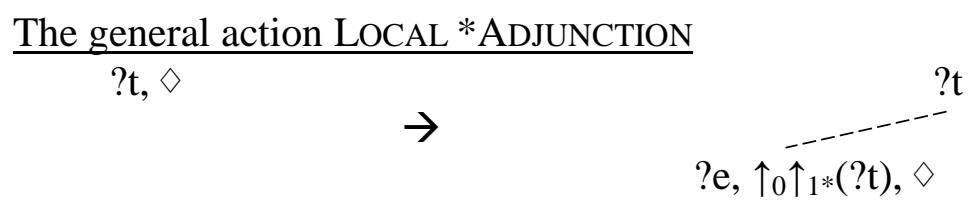

An unfixed relation is indicated by a dashed line. The unfixed node is annotated with $\uparrow_{0} \uparrow_{1 *(? t)}$. This constraint ensures that the node will be resolved in a local propositional structure. ${ }^{14}$ Note that the pointer $\diamond$ is located at an unfixed node; this allows an NP to be parsed without waiting for a verb to be encountered. ${ }^{15}$

\footnotetext{
${ }^{14}$ The detail of $\uparrow_{0} \uparrow_{1 *}(? \mathrm{t})$ is irrelevant; what is important is that it ensures that an unfixed node is resolved in a local structure. Still, here is a brief explanation. With the Kleene star $*, \uparrow_{0} \uparrow_{1 *}$ is a sequence $\langle 0, \mathrm{x}\rangle$, where $\mathrm{x}$ is an arbitrary succession of 1 , as in $\langle 0\rangle,\langle 0,1\rangle,\langle 0,1,1\rangle$. Recall that
} 
There are two options for resolving an unfixed node: lexical and non-lexical. In Japanese, a case particle encodes an action to resolve an unfixed node. For example, the nominative particle $g a$ resolves an unfixed node as a "subject" node. ${ }^{16}$ This is illustrated in (44), where a dashed line has become a solid line (representative of a fixed node).

\section{$\underline{\text { Resolving an unfixed node with the parse of } g a}$}

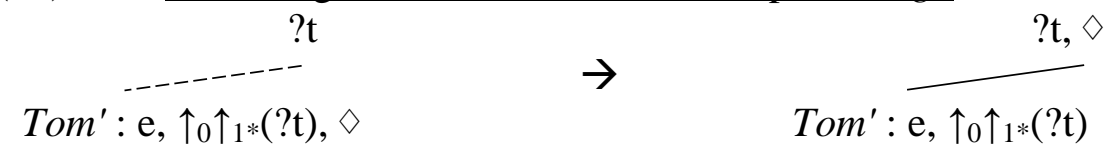

The second option is to execute UnIFICATION. This general action merges the node descriptions of an unfixed node and a fixed node, as a result of which an unfixed node is structurally resolved. UNIFICATION plays a central role in parsing focus elements in clefts (see Section 4 for details).

In the rest of this subsection, we shall illustrate the DS mechanism with the parse of the simple Japanese sentence shown in (45).

\section{(45) Tom-ga yon-da \\ T-NOM read-PAST \\ 'Tom read it.'}

Starting with the AXIOM, the rule of LOCAL *ADJUNCTION (43) posits a type-erequiring unfixed node. This unfixed node is annotated by the parse of the initial item Tom.

$$
\frac{\text { Parsing Tom }}{? \mathrm{t}}
$$

$\operatorname{Tom}^{\prime}: \mathrm{e}, \uparrow_{0} \uparrow_{1} *(? \mathrm{t}), \diamond$

The unfixed node is resolved as a subject node by the nominative particle $g a$ (see (44) above). In (47), $\uparrow_{0} \uparrow_{1 *(? t)}$ is omitted since the node in question is now resolved as a subject node.

\section{Parsing Tom-ga}

$? \mathrm{t}, \diamond$

$$
\text { Tom' }: \overline{\mathrm{e}}
$$

DS trees are binary-branching with an argument on the left and a functor on the right. If a nonlocal structure is crossed, $\uparrow_{0}$ is involved more than once as in $\uparrow_{0} \uparrow_{1} \uparrow_{0}$, contradicting with $\uparrow_{0} \uparrow_{1}$. ${ }^{15}$ The variants of LOCAL *ADJUNCTION (i.e., *ADJUNCTION, GENERALISED ADJUNCTION) are not employed in this paper; we assume NPs are parsed only by LOCAL *ADJUNCTION (Author 2013). ${ }^{16}$ Since DS dispenses with the syntactic vocabulary, "subject" is used for presentation purposes. A subject node refers to the left-daughter of a root node in a propositional tree. We simply hold that $g a$ encodes the action to resolve an unfixed node as a subject node, ignoring complex data such as "multiple nominative constructions" and "ga-marked object" (see Nakamura et al. 2009). 
The next item is the verb yon- 'read.' Since Japanese is fully pro-drop, it is assumed that a verb creates a propositional template with argument slots. Thus, the transitive verb yon-projects the template (48) with two argument slots. At the subject node, ? $\exists \mathrm{x} . F o(\mathrm{x})$ requires that $\mathrm{U}$ will be saturated. ( $F o$ is a "formula" predicate.) The same goes for the object node.

$$
\begin{aligned}
& \text { Output structure of parsing yon- } \\
& ? \mathrm{t}, \diamond \\
& \mathrm{U}: \mathrm{e}, \widehat{? \exists \mathrm{x} . F o(\mathrm{x}) \quad ?(\mathrm{e} \rightarrow \mathrm{t})} \\
& \mathrm{V}: \mathrm{e}, ? \exists \mathrm{y} \cdot F o(\mathrm{y}) \quad y o n^{\prime}: \mathrm{e} \rightarrow(\mathrm{e} \rightarrow \mathrm{t})
\end{aligned}
$$

In non-pro-drop languages, a verb does not create a template like (48), but encodes information about the arguments. For instance, the content of run in English is strictly notated as $\lambda \mathrm{x}$.[run'(x)], which specifies the number of arguments selected.

In (47), the subject node is already present and collapses with the subject node created by yon-in (48). This collapse is harmless because (i) the subject node created by yon- is annotated with a metavariable $\mathrm{U}$ and (ii) a metavariable is the weakest form of content, compatible with any formula. So, the parse of yon-is updated from (47) to (49), where ? $\exists \mathrm{x} . F o(\mathrm{x})$ is no longer present since $\mathrm{U}$ has received a full specific value, Tom'.

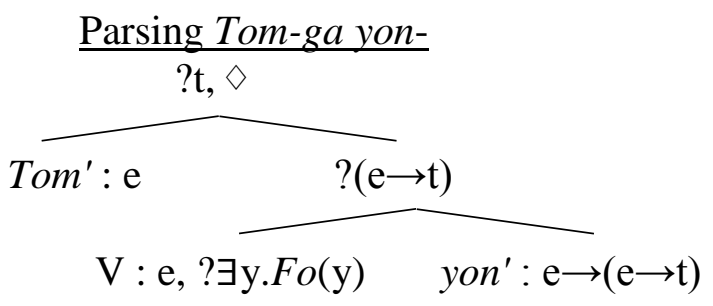

The tree (49) contains the requirement that the metavariable $\mathrm{V}$ needs to be saturated $(? \exists y . F o(y))$. This is satisfied by running SuBSTITUTION to saturate V with hon' (denoting a book), provided that it is an appropriate entity. The other requirements are met by running ELIMINATION (twice, for the object-predicate pair and the subjectpredicate pair).

$$
\begin{aligned}
& \underline{\text { SUBSTITUTION + ELIMINATION }} \\
& \text { yon' }^{\prime}\left(\text { hon }^{\prime}\right)\left(\text { Tom }^{\prime}\right): \mathrm{t}, \diamond \\
& \text { Tom' }: \mathrm{e} \quad \frac{\text { yon }^{\prime}\left(\text { hon }^{\prime}\right): \mathrm{e} \rightarrow \mathrm{t}}{\text { hon }^{\prime}: \mathrm{e} \quad \text { yon }^{\prime}: \mathrm{e} \rightarrow(\mathrm{e} \rightarrow \mathrm{t})}
\end{aligned}
$$

The structure (50) is well-formed in that no outstanding requirements remain, and it represents the asserted content of (45) relative to a context where Tom read a book.

We have outlined the DS mechanism and the application of these tools to Japanese. As will be shown in the next subsection, this basic machinery is applicable 
This is the accepted version of a final article which will be published by Elsevier in Language Sciences. Final published version available at: 10.1016/j.langsci.2016.03.003

Accepted Version downloaded from SOAS Research Online: http://eprints.soas.ac.uk/22203/

to Rangi without substantive modification. The main difference introduced for Rangi will be that the overt subject expression is projected onto a LINKed tree.

\subsection{LINK Relations}

In the last subsection, DS trees were constructed in isolation; that is, the parser builds a single tree at a time. However, it is also possible for two trees to be constructed in tandem. This is the case in relative clauses, for example (Cann et al. 2005: Ch.3-4), and will be shown later to be the appropriate manner in which to model clefts.

The relationship between two trees is defined via a "LINK" relation. The LINK machinery has been exploited to analyse overt subject expressions in Bantu languages. This will be illustrated with the simple Rangi sentence (51). ${ }^{17}$
niúni $\quad n$-íyó-terek-a
chá-kurya
$1^{\text {st }}$.SG.PP SM. $1^{\text {st }}$.SG-PROG-cook-FV 7-food
'I am cooking food.'

As with Japanese, the Rangi tree-update starts from the AXIOM. Subsequently, the subject NP nitini 'I' is to be parsed and a LINK relation is induced by the general action LINK ADJUNCTION.

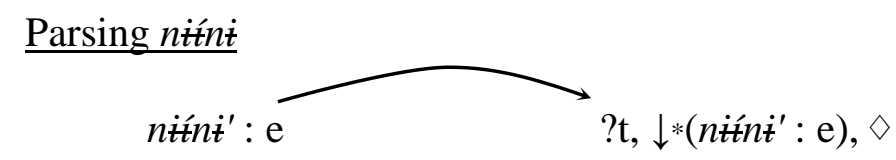

LINK ADJUNCTION posits a requirement that a copy of the information encoded in nitni will be present somewhere in the parallel tree. LINK is, therefore, a formal pairing of one tree to another by virtue of the presence of a shared term, in this case, the content of nitnit.

Parsing the rest of the string leads to the building of the main tree. We model the Rangi subject maker as responsible for the projection of a locally unfixed node from a ?t-node. In the case of $n$-, a locally unfixed node is annotated with speaker' : e. (In other instances, a subject marker would posit a metavariable; if a subject NP is parsed, the metavariable is saturated immediately with the content of the NP.) In this way, the LINKed node for a subject NP acts as background against which the main tree is interpreted, as shown in (53).

\footnotetext{
${ }^{17}$ Previous analyses have proposed that subject expressions in Bantu languages can be modelled either on non-locally unfixed nodes or on LINKed nodes (a locally-unfixed-node analysis of subject NPs is not available since Bantu languages do not have overt case). Author (2012) proposes that subject NPs in Rangi (and in Bantu more broadly) are more appropriately modelled as annotating LINKed nodes. This is due in part to an attempt to restrict the application of general actions as well as the observation that overt subject NPs in Bantu languages are often topical (cf., Bresnan \& Mchombo 1987, Demuth 1990, Marten 2011, Zerbian 2006). Since multiple parsing strategies are available at any given time in DS (Cann et al. 2005), this decision does not reflect a cross-linguistic difference in the parse process but rather that the lexically-specified content is language-specific and can result in distinct tree-growth processes.
} 
This is the accepted version of a final article which will be published by Elsevier in Language Sciences. Final published version available at: 10.1016/j.langsci.2016.03.003

Accepted Version downloaded from SOAS Research Online: http://eprints.soas.ac.uk/22203/

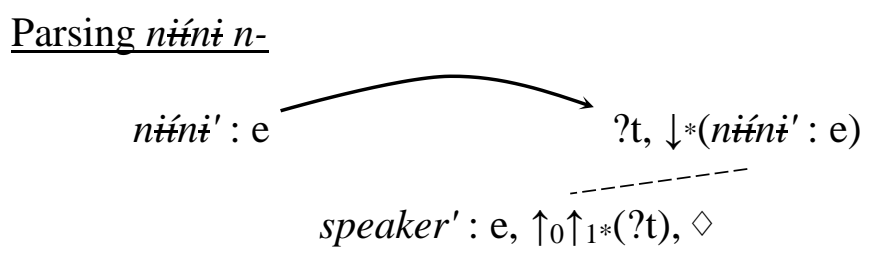

The next element is the progressive marker íyó-. Preverbal tense-aspect markers in Rangi are regarded as introducing a subject node and a predicate node. This predicateargument structure resolves the unfixed node introduced by the subject marker.

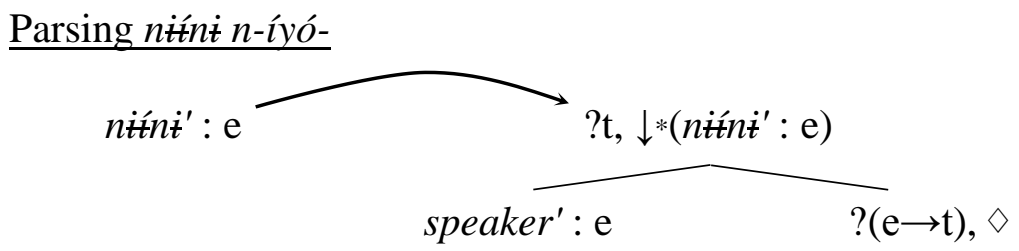

The ? $(\mathrm{e} \rightarrow \mathrm{t})$-node is annotated by the verb stem -terek 'cook.' As -terek is a transitive verb, it also creates an object node. (The final vowel $-a$ indicates that no further predicate-argument structure can be built, and moves the pointer $\diamond$ to the argument node to preclude the construction of any nodes below this point.) The object node is annotated subsequently by the object NP chákurya 'food.' After ELIMINATION is performed, the final tree (55) emerges.

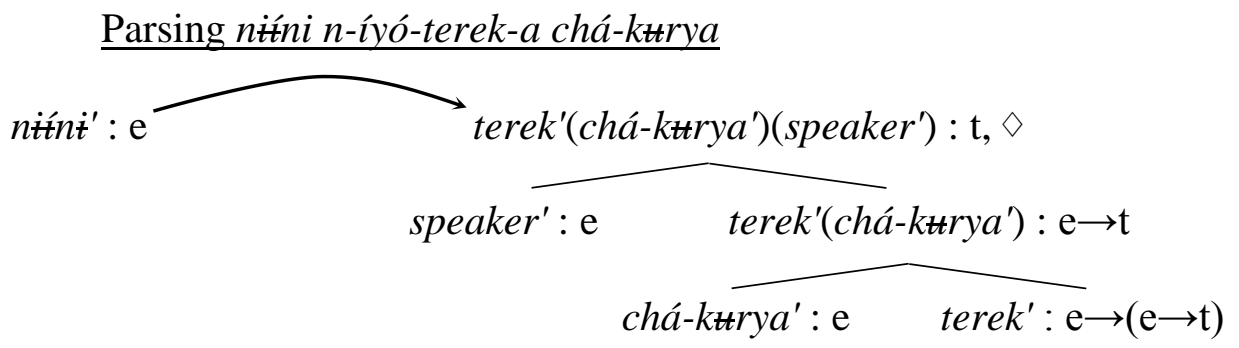

The root node is annotated with the proposition expressed by nitni n-íyó-terek-a cháktrya 'I am cooking food.'

LINK is a formal means through which two trees are connected on the basis of a shared term. This structure pairing proceeds incrementally. The parser first builds one tree (simplex or complex). A LINK relation connecting one node to another is then initiated, and the emergent tree carries the requirement that it will share a term found in the original tree. In the case of a subject NP in Rangi, a LINK relation is launched from a type-e node to a ?t-node. In relative clauses, a LINK relation goes from a type$\mathrm{t}$ node (i.e., top node of the tree for a relative clause) to a ?e-node (i.e., node for a head noun). ${ }^{18}$ Indeed, a LINK relation may be introduced from a node of an arbitrary type to another of an arbitrary type. As will be seen in Section 4, our analysis of clefts in Japanese and Rangi utilises a LINK relation from a type-t node to a ?t-node.

\footnotetext{
${ }^{18}$ This differs from the standard analysis of relatives where a relative clause is of type $<e, t>$ (e.g., Heim \& Kratzer 1998). In DS, a structure for a relative clause is of type t, and the modification of a head noun is captured in the epsilon calculus (Cann et al. 2005).
} 
This is the accepted version of a final article which will be published by Elsevier in Language Sciences. Final published version available at: 10.1016/j.langsci.2016.03.003

Accepted Version downloaded from SOAS Research Online: http://eprints.soas.ac.uk/22203/

\subsection{Summary}

DS models knowledge of language as a set of procedures/constraints used to build up a semantic tree reflecting incremental parsing in real time. It should be emphasised that what is constructed is a semantic representation; a string is directly mapped onto a semantic tree without an intermediate level of syntactic structure. The initial state of tree-update is determined as the AXIOM, and subsequently enriched by a combination of general, lexical, and pragmatic actions. Tree-update is complete iff all requirements are satisfied. DS structure-building may involve the introduction of an unfixed node, whereby a node position is initially underspecified and resolved later. This resolution may be driven lexically (e.g., parse of a case particle in Japanese) or non-lexically (i.e., general action of UNIFICATION). Another important DS apparatus is LINK. The parser may build two distinct trees in parallel, relating one to the other by virtue of a shared term; this term-sharing is ensured by imposing a requirement that a copy of a term in one tree will appear in the other tree. Based on these tools, a dynamic account of Japanese and Rangi clefts will be articulated in the next section.

\section{The Dynamic Account}

Having provided an overview of the Dynamic Syntax (DS) framework, the current section goes on to present an explicit account of Japanese and Rangi clefts. As will be detailed below, our account of clefts in the two languages relies on the DS assumption that cross-linguistic variation is reflected in the balance of which portions of actions are encoded lexically or non-lexically in individual languages (Cann et al. 2005).

\subsection{Japanese Clefts}

As surveyed in Section 2.1, a Japanese cleft consists of (i) a presupposition clause followed by the nominaliser no and the topic marker $w a$, (ii) a type-e focus element, and (iii) the copula $d a$. As illustrated in (56), the case-marking of the focus Ruth is optional. ${ }^{19}$ We shall call clefts with a case-marked focus clefts $+\mathrm{C}$ and clefts without a case-marked focus clefts $-\mathrm{C}$.

(56) [hashi-tta no]-wa Ruth(-ga) da

[run-PAST NO]-TOP R(-NOM) COP

'It is Ruth that ran.'

A common assumption in the literature is that clefts ${ }_{+\mathrm{C}}$ and clefts ${ }_{-\mathrm{C}}$ are structurally distinct (Hiraiwa \& Ishihara 2012, Hoji 1990, Kizu 2005, Koizumi 2000, Kuwabara 1996, Takano 2002). For instance, Hiraiwa \& Ishihara (2012) and Hoji (1990) hold that movement is involved only in clefts $+\mathrm{C}$; Kizu (2005) maintains that movement occurs in both types of cleft but with different structures assigned in each instance.

This structural dichotomy of clefts $+\mathrm{C}$ and clefts ${ }_{-\mathrm{C}}$ is challenged by the multiple foci data. Recall that in multiple foci (without a coordination reading), only the final focus may occur without case-marking.

\footnotetext{
${ }^{19}$ For many speakers, the $g a$-marking of a focus is quite degraded (Hiraiwa \& Ishihara 2012), but such examples are attested spontaneously (Cho et al. 2008, Author 2013). We thus assume that the $g a$-marking of a focus is not ungrammatical, though it often lowers acceptability.
} 
This is the accepted version of a final article which will be published by Elsevier in Language Sciences. Final published version available at: 10.1016/j.langsci.2016.03.003

Accepted Version downloaded from SOAS Research Online: http://eprints.soas.ac.uk/22203/

$$
\begin{aligned}
& \text { tabe-ta no]-wa Ruth*(-ga) } \\
& \text { ringo da } \\
& \text { [eat-PAST NO]-TOP R(-NOM) apple COP } \\
& \text { Lit. 'It is Ruth } \mathrm{i}_{\mathrm{i}} \text { and it is an apple } \mathrm{e}_{\mathrm{j}} \text { that } \mathrm{e}_{\mathrm{i}} \text { ate } \mathrm{e}_{\mathrm{j}} \text {.' }
\end{aligned}
$$

In clefts with partially case-marked foci such as (57), clefts ${ }_{+C}$ and clefts $-_{-}$are realised in a single clause. Thus, it is not obvious how radically different structures could be assigned to the single cleft string. One may assume that the cleft (57) is assigned only a single structure for clefts $_{+}$, but with a case marker being phonologically dropped from ringo during post-syntactic computations. This would correctly predict the licit cluster Ruth-ga ringo. It is not clear, however, how this analysis can predict the illicit cluster Ruth ringo, as nothing seems stop us from reasoning that the cleft is assigned a structure for clefts $+\mathrm{C}$ with case particles dropped phonologically from both foci.

The multiple foci data lend themselves to a uniform account, where "uniform" means that (i) the two types of cleft are mapped onto an identical structure and that (ii) $n o$ is treated identically regardless of the case-marking of a focus. ${ }^{20}$ Section 4.1.1 develops such a uniform account, and Section 4.1.2 turns to the multiple foci issues.

\subsubsection{The Uniform Account}

Let us first examine the cleft $+\mathrm{C}$ where the focus Ruth is marked by the nominative case marker $g a(58)$.

\section{(58) [hashi-tta no]-wa Ruth-ga da \\ [run-PAST NO]-TOP R-NOM COP \\ 'It is Ruth that ran.'}

The presupposition clause hashi-tta yields (59). The argument node is annotated with $\mathrm{x}$, a content of the gap. ${ }^{21}$

\footnotetext{
${ }^{20}$ Other data have also motivated a bifurcated view of clefts. First, clefts $+\mathrm{C}$ are sensitive to an island, while clefts ${ }_{C}$ are not (Hoji 1990). This contrast is amenable to our uniform account. Unlike non-island examples, a locally unfixed node cannot be used for a cleft with an island due to its "local" nature. However, a focus may be parsed at a LINKed node. As contended in Author (2013), the parse of a case particle at such a LINKed node aborts a tree-update. Thus, the parse of a cleft ${ }_{C}$ string (but not a cleft ${ }_{+C}$ string) may lead to a well-formed tree.

Second, no can be substituted with a noun like mono 'thing' only in clefts_C (Hiraiwa \& Ishihara 2012). But if such substitution occurs, the string is not a cleft (though it is still a "specificational" sentence in Nishiyama's (2003) sense) but a relative clause string, as illustrated in (i).

(i) [[Ruth-ga tabeta $]$ mono $]-w a$ ringo $\left(*_{-}-o\right)$ da

[[R-NOM ate] thing]-TOP apple(-ACC) COP

'The thing which Ruth ate is an apple.'

The impossibility of the case-marking of the pre-copula item ringo 'apple' in (i) is due to the more general fact that in the structure "NP${ }_{1}-w a \mathrm{NP}_{2} d a$," $\mathrm{NP}_{2}$ cannot be case-marked.

Finally, the nominative-genitive conversion may be licensed only in clefts ${ }_{\mathrm{C}}$ (Hiraiwa \& Ishihara 2012). At present, this is a residual issue. One option would be to assign a suitable entry to the genitive, in which case the pattern may be predicted through lexical stipulations.

${ }^{21}$ A gap is theoretically construed in various manners such as "trace" and "null pronoun." In DS, the concept of "trace" is not posited since movement operations are not assumed. What is usually called "trace" is expressed as a variable (formally, an epsilon term with an abstract predicate (Kempson \& Kurosawa 2009)). In contrast, a null pronoun is notated as a metavariable, which is updated to a variable. Thus, though the notations of the DS-analogue of "trace" and null pronoun differ, they are both expressed as a variable in the final representation.
} 
This is the accepted version of a final article which will be published by Elsevier in Language Sciences. Final published version available at: 10.1016/j.langsci.2016.03.003

Accepted Version downloaded from SOAS Research Online: http://eprints.soas.ac.uk/22203/

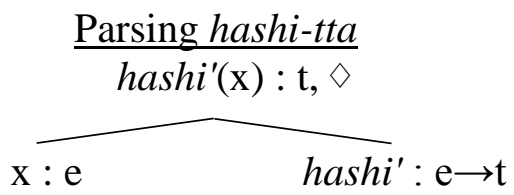

Cann et al. (2005) claim that the nominaliser no LINKs a type-t node to a ?e-node, and that the topic marker $w a$ then LINKs the ?e-node to a ?t-node. The sequence no$w a$ thus involves two LINK relations. Whilst this is formally possible, we simplify this analysis by regarding the sequence no-wa as a cleft marker which introduces a single LINK relation from a type-t node to a ?t-node (Author 2013).

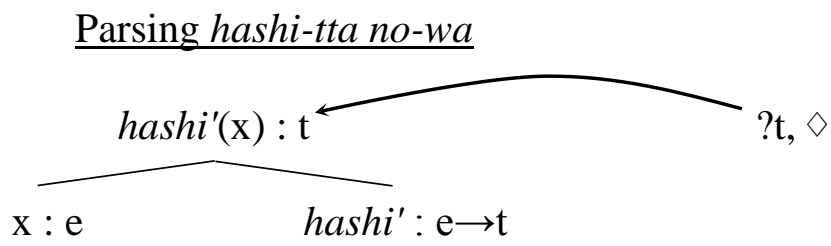

The general action of LOCAL*ADJUNCTION then introduces a locally unfixed ?e-node. This unfixed node is annotated by the focus Ruth, and is immediately resolved as a subject node by the nominative case particle $g a$.

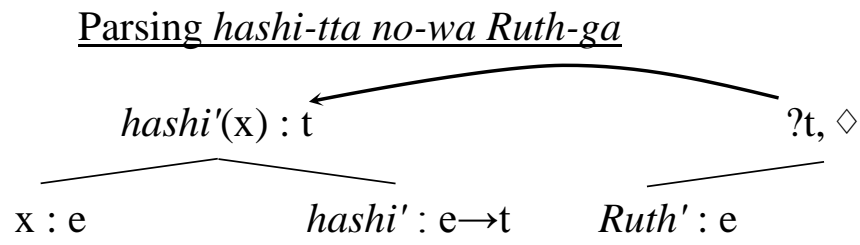

Next, the copula $d a$, which is assumed to be a propositional pro-form (Author 2013; see also Pustet 2003: 60-1), provides a type-t metavariable BE at the ?t-node.

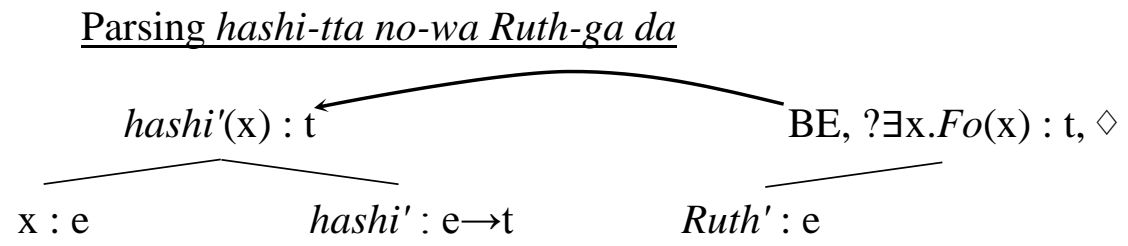

The emergent tree is fleshed out relative to the presupposition tree. In particular, the type-t metavariable BE triggers SUBSTITUTION, ${ }^{22}$ which copies the presupposition tree onto the emergent tree. As a result, the subject node is annotated with both Ruth' and $\mathrm{x}$, but these formulae harmlessly collapse because the variable $\mathrm{x}$ is compatible with any formula like Ruth'. After ELIMINATION is run, the final state (63) arises.

\footnotetext{
${ }^{22}$ In Author (2013), a metavariable BE triggers the pragmatic action REGENERATION, which reruns a set of previous actions. REGENERATION outputs a correct result here, but a problem arises in the treatment of multiple foci (see footnote 24 ).
} 
This is the accepted version of a final article which will be published by Elsevier in Language Sciences. Final published version available at: 10.1016/j.langsci.2016.03.003

Accepted Version downloaded from SOAS Research Online: http://eprints.soas.ac.uk/22203/

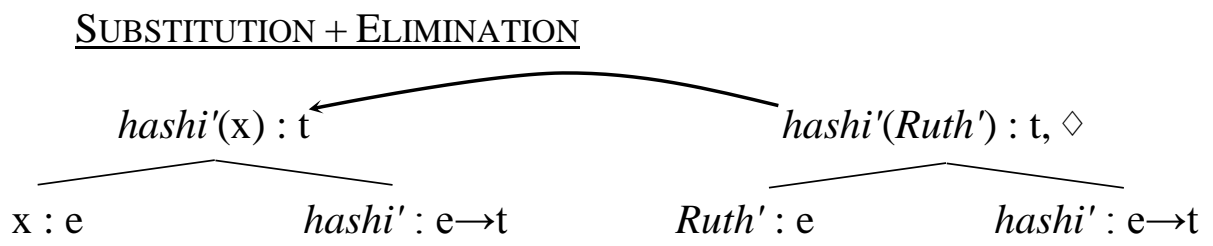

The formula at the current node represents the truth-conditional content of the cleft string (58) (tense aside): 'It is Ruth that ran.'

Crucially, the above analysis of cleft ${ }_{+C}(58)$ is straightforwardly applicable to its cleft $_{\mathrm{C}}$ counterpart (64).

(64) [hashi-tta no]-wa Ruth da

[run-PAST NO]-TOP R COP

'It is Ruth that ran.'

The tree update proceeds identically up to the parse of Ruth. In (64), Ruth is caseless, and thus an unfixed node for Ruth is not fixed at this stage. The copula $d a$ then posits a metavariable BE, triggering SUBSTITUTION (copying the presupposition tree onto the emergent tree).

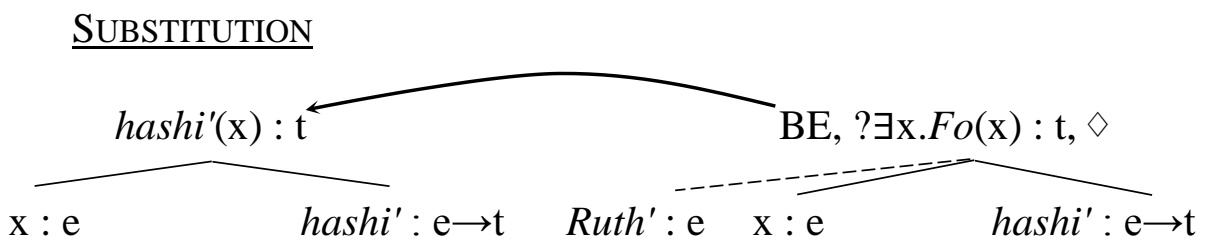

In (65), there is a type-e unfixed node with a specific formula and a type-e fixed node with a variable. This environment licenses UNIFICATION, a general action to combine the annotations of two nodes (one fixed and the other unfixed), to the effect that the structural underspecification is resolved. ${ }^{23}$

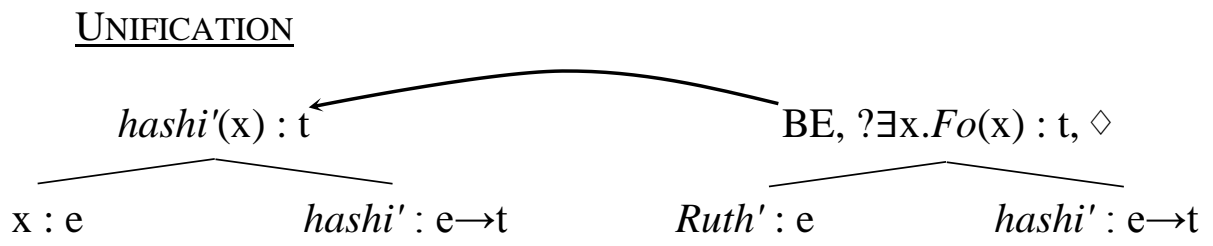

After EliminAtion is run, the output is the same as the tree (63). This tree-identity makes sure that the two clefts $(58) /(64)$, which minimally differ in the case-marking of the focus Ruth, are truth-conditionally equivalent.

We have proposed a uniform analysis of Japanese clefts. In this analysis, the string-structure pair is not predetermined. Put differently, the same set of actions is potentially used for a cleft no matter whether a focus is case-marked. If the parser detects a case marker at a focus position, an unfixed node for the focus is resolved lexically (i.e., lexical action encoded in a case marker); otherwise, an unfixed node is resolved non-lexically (i.e., UNIFICATION). The reader may still wonder whether our

\footnotetext{
${ }^{23}$ UNIFICATION is applicable to an adjunct focus without a particle, like sono-ekimae '(in front of) that station' in (14). Thus, our analysis accommodates adjunct focus examples too.
} 
This is the accepted version of a final article which will be published by Elsevier in Language Sciences. Final published version available at: 10.1016/j.langsci.2016.03.003

Accepted Version downloaded from SOAS Research Online: http://eprints.soas.ac.uk/22203/

analysis is uniform because UNIFICATION applies only for a caseless focus. But it is uniform in two senses: unlike extant analyses, (i) lexical ambiguity is not involved, especially for no and (ii) structural ambiguity is not hypothesised either in that the same structure emerges regardless of the case-marking of a focus.

\subsubsection{Multiple Foci and Case-Marking}

In our account, a focus is parsed on a locally unfixed node. According to the DS tree logic (Blackburn \& Meyer-Viol 1994), a node in a tree must have a unique position. Note that a locally unfixed node will be fixed somewhere in a local structure. Thus, when two locally unfixed nodes are induced in a local structure, they are one and the same. For instance, consider the tree (67). The annotation $\uparrow_{0} \uparrow_{1 *(? t)}$ dictates that the node position to be resolved is a disjunction of every potential node within this local structure. As the (putative) two unfixed nodes equally encode this restriction, they are treated as the same node.

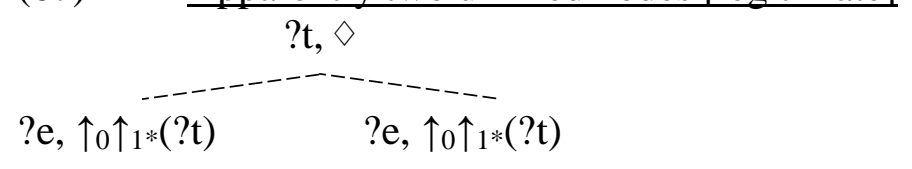

Nothing is wrong with (67) since it just describes a tree state where there is virtually a single unfixed node. But a problem arises if these nodes are annotated with distinct formulae, as in (68). In this tree, the node descriptions are inconsistent, since a single node is annotated with inconsistent formulae, Mary' and Tom'.

(68) Apparently two unfixed nodes with distinct formulae [illegitimate]

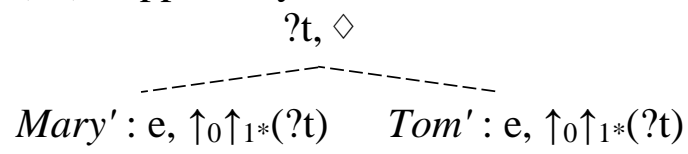

This tree-logic nature of unfixed node imposes a strong constraint on tree-growth:

(69) The Unique Unfixed-Node Constraint

When locally unfixed nodes have incompatible formulae within the same local structure, inconsistency of node descriptions arises and a tree update clashes.

This is a corollary of the tree-logic, though it is termed as the "Unique Unfixed-Node Constraint" for illustration purposes. As we shall see below, the constraint explains the case-particle distribution over multiple foci in Japanese.

Firstly, let us consider a simple example of multiple foci (70).

(70) [Ruth-ga tabe-ta no]-wa ie-de ringo-o da

[R-NOM eat-PAST NO]-TOP house-in apple-ACC COP

Lit. 'It is in the house and it is apples that Ruth ate.'

The first focus ie 'house' is parsed on an unfixed node, and it is immediately resolved by $d e$ 'in.' Then, an unfixed node is introduced once again to parse the second focus ringo 'apple.' Since the unfixed node for the first focus $i e$ has been resolved, there is only a single unfixed node. Thus, inconsistency of node descriptions does not occur, 
This is the accepted version of a final article which will be published by Elsevier in Language Sciences. Final published version available at: 10.1016/j.langsci.2016.03.003

Accepted Version downloaded from SOAS Research Online: http://eprints.soas.ac.uk/22203/

satisfying the constraint (69). The unfixed node for the second focus ringo is resolved immediately by the case particle $o$ in (70).

Secondly, recall that only the final focus may be caseless (unless a coordination interpretation obtains).

(71) [Ruth-ga tabe-ta no]-wa ie-de ringo da [R-NOM eat-PAST NO]-TOP house-in apple COP Lit. 'It is in the house and it is apples that Ruth ate.'
*[Ruth-gatabe-ta no]-wa ie ringo(-o) da
[R-NOM eat-PAST NO]-TOP house apple(-ACC) COP
Int. 'It is in the house and it is apples that Ruth ate.'

In (71), the first focus ie 'house' is parsed on an unfixed node and is resolved by de 'in.' As an unfixed node is no longer in place, the parser safely introduces another unfixed node for the second focus ringo 'apple.' This unfixed node cannot be resolved lexically due to the lack of case-marking, but it is resolved by the rule of UNIFICATION after the copula $d a$ is parsed. This accounts for why (71) is grammatical. ${ }^{24}$ In contrast, in (72), an unfixed node for the first focus ie cannot be fixed as it lacks a particle. Further, UNIFICATION cannot be run either as this action presupposes that there is a propositional structure but such structure is unavailable until the copula $d a$ is parsed. Thus, when an additional unfixed node is induced for the second focus ringo, a single unfixed node is annotated with distinct formulae (i.e., the contents of $i e$ and ringo), violating the constraint (69). This is why (72) is ungrammatical.

For completeness, consider clefts with three foci (73), where a particle may be dropped only from the final focus ringo 'apple.'

(73) [tabe-ta no]-wa Ruth-ga ie-de ringo(-o) da [eat-PAST NO]-TOP R-NOM house-in apple(-ACC) COP Lit. 'It is Ruth, it is in the house, and it is apples that ate.'

This complex example is readily dealt with: an unfixed node for any non-final focus must be immediately resolved by a case particle; otherwise, when another unfixed node is induced for the next focus, inconsistency of node descriptions occurs. As for the final focus, an unfixed node may be resolved non-lexically by UNIFICATION after the copula $d a$ is parsed. Thus, only the final focus may appear without a particle.

In sum, the recalcitrant data on multiple foci are explained as an outcome of the incremental growth of a semantic tree. This account also points towards some future directions. For instance, some scholars assume the clause-mate condition on multiple foci (Koizumi 2000, Takano 2002): foci cannot be associated with multiple clauses of different embedding levels. This is not captured in our account, but the condition is contentious (see Fukui \& Sakai 2003) and it might be more appropriate to call it a "tendency" rather than a condition. The question of how best to express this tendency,

\footnotetext{
${ }^{24}$ In Author (2013), BE triggers REGENERATION (see footnote 22), but this poses a problem. If REGENERATION were run for (71), a single unfixed node would be annotated with the contents of ringo and Ruth, violating the constraint (69). Our current account avoids this problem; BE triggers SUBSTITUTION, in which case a single unfixed node is annotated with the content of ringo alone.
} 
This is the accepted version of a final article which will be published by Elsevier in Language Sciences. Final published version available at: 10.1016/j.langsci.2016.03.003

Accepted Version downloaded from SOAS Research Online: http://eprints.soas.ac.uk/22203/

however, remains. One possibility is to view it as a performance constraint on the parser (see Kiaer 2014), but a detailed investigation should await other occasions.

\subsection{Rangi Clefts}

We now turn our attention to Rangi clefts. As was outlined in Section 2.2, a Rangi cleft consists of (i) the copula $n \dot{t}$, (ii) a type-e focus, and (iii) a presuppositional clause which acts as the background against which the cleft is assessed. As was also seen for Japanese in Section 4.1, Rangi clefts are analysed as involving a LINK relation between the trees which host the information provided by the focus and the presupposition clause. This parsing strategy stems from the observed cross-language parallels between clefts and relatives (Kempson et al. 2011, Cheng \& Downing 2013: 141), as well as reflecting the focus effects associated with clefs. Kempson et al. (2011) also model clefts in siSwati (a Bantu language spoken in Southern Africa) by recourse to LINK. As will be argued below, our analysis fits neatly with the uniform analysis forwarded for Japanese clefts, as well as exhibiting a reflex of the Unique Unfixed-node Constraint.

Firstly, let us consider the basic example of the Rangi cleft (74).

(74) $[n \dot{t} \quad n \ddot{t} n \dot{t}] \quad n$-íyó-tï̈j-a

[COP $1^{\text {st }}$.SG.PP] SM. $1^{\text {st }}$.SG-PROG-run-FV

'It is me that is running.'

As is always the case, the parse starts with the AxIOM. The first item is the copula nt́ In the last subsection, the Japanese copula $d a$ is analysed as introducing a type-t metavariable. The analysis of the Rangi copula $n t$ also encompasses the positing of a metavariable but its semantic type is assumed to be of $\mathrm{e} \rightarrow \mathrm{t}$ and the process is to create the associated argument-predicate structure (Author 2012). In fact, this analysis of the Rangi copula nt́ is preceded in Cann's (2006) treatment of the English copula be. The argument node provided by the copula $n t$ is annotated by the post-copula item nitnt 'I.' After EliminATION is executed, the tree (75) arises. ${ }^{25}$

$$
\begin{aligned}
& \text { Parsing nt́ nítnít } \\
& \mathrm{BE}(n \dot{t} n \dot{n}): \mathrm{t}, \diamond \\
& \text { nitnt' }: \text { e } \quad \mathrm{BE}: \mathrm{e} \rightarrow \mathrm{t}
\end{aligned}
$$

A LINK relation is initiated from the subject node to a ?t-node, with the constraint that the type-e content nitni' will be found in this emergent tree. An unfixed node is then projected from this ?t-node and annotated with the type-e content nín $\dot{t}^{\prime}$, meeting the term-sharing requirement of the LINK relation.

\footnotetext{
${ }^{25}$ Unlike the metavariable posited for the Japanese and English copulas, the metavariable posited for the Rangi copula $n t$ is not saturated. The claim that the Japanese copula $d a$ is a pro-form in need of saturation is motivated by the observation that $d a$ appears in certain ellipsis constructions like stripping/sluicing (Author 2013). Similarly, Cann (2006) notes that the English copula be has a use in ellipsis. In contrast, the Rangi copula $n \hat{t}$ does not exhibit comparable ellipsis use (Author 2012), and it is reasonable to hold that $n t$ is a pro-form that does not need to be saturated.
} 
This is the accepted version of a final article which will be published by Elsevier in Language Sciences. Final published version available at: 10.1016/j.langsci.2016.03.003

Accepted Version downloaded from SOAS Research Online: http://eprints.soas.ac.uk/22203/

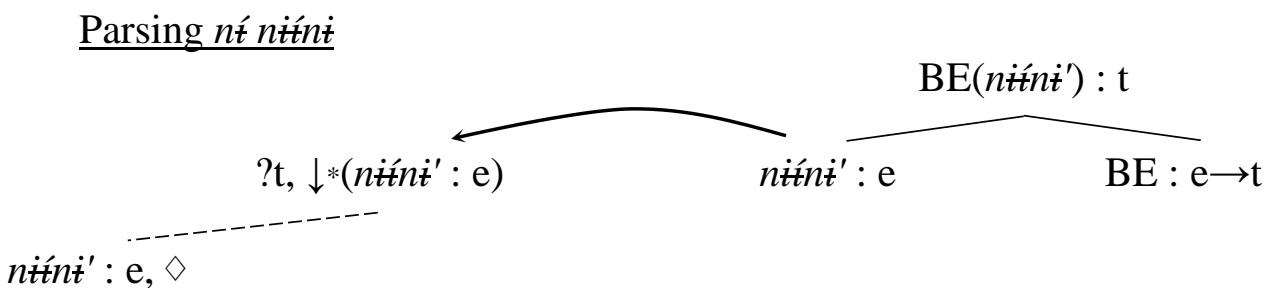

The subject marker on the main verb introduces a locally unfixed node annotated with a metavariable. This metavariable can be saturated immediately as nitn $\dot{t}^{\prime}$ because it is interpreted against the backdrop of the focus information: nit́nt' : e. The preverbal tense-aspect marker íó- projects a subject-predicate structure, which resolves the unfixed node as a subject node.

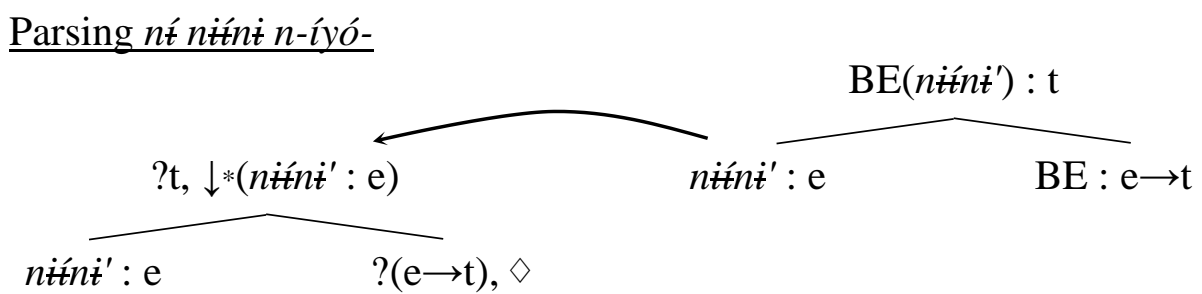

Parsing the verb stem $t i i j$ 'run' introduces the content $t i i j$ ' and the semantic type $\mathrm{e} \rightarrow \mathrm{t}$ to the predicate node. With all the nodes specified for content and type, ELIMINATION can apply, removing any outstanding requirements and leading to the final tree.

(78) Parsing né níńt n-íyó-tïij-a

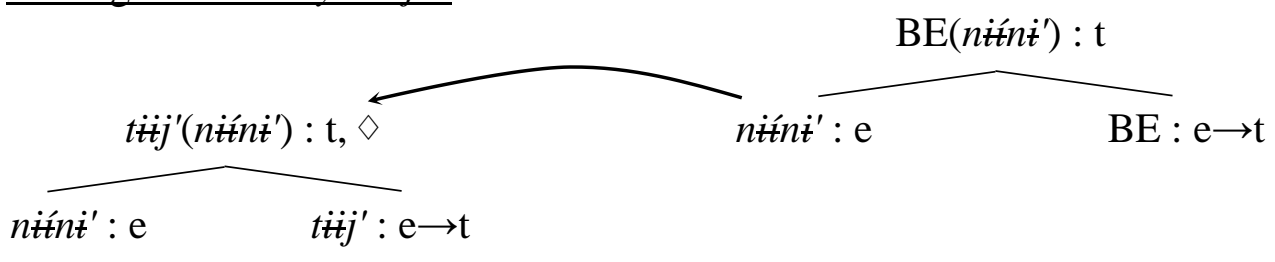

The content at the current propositional node represents the truth-conditional content of the cleft string parsed (74): 'It is me that is running.'

As discussed in Section 2.2, the future tense in Rangi is formed through the use of an auxiliary and a main verb. Whilst declarative main clauses exhibit post-verbal auxiliary placement, the order of the auxiliary with respect to the main verb is reversed in future tense clefts, as illustrated in (79).

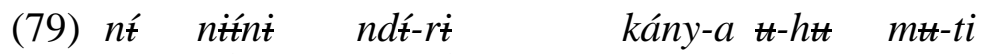
COP $1^{\text {st }}$.SG.PP SM. $1^{\text {st }}$.SG-AUX cut-FV DEM-3 3-tree
'It is me that will fell this tree.'

In the following discussion, we shall outline the way in which the analysis that has been developed for Rangi (and indeed Japanese) clefts is extendable to the auxiliaryverb ordering. Moreover, we shall show that the word order alternation associated with Rangi future tense clefts contributes further cross-linguistic evidence in support of the Unique Unfixed-node Constraint. 
The stages involved in parsing a cleft string such as (79) are much the same as those that have been developed thus far. In the preceding section, we proposed that the copula $n \dot{t}$ projects a subject node and a predicate node which is annotated with the metavariable BE. The subject node is immediately annotated by the next item, nitnit 'I'. A LINK relation is then initiated from the subject node to a ?t-node, with the requirement that the emergent tree will also involve the type-e content nitnit. From the ?t-node, an unfixed node is also posited. The subject marker $n d \hat{t}^{-}$creates a locally unfixed node annotated with a metavariable for the first person singular entity. This metavariable is saturated immediately as nitni', given that the structure present at this time has been updated with respect to this content, as represented in $\downarrow *\left(n \dot{t} n \dot{t}^{\prime}:\right.$ e) .

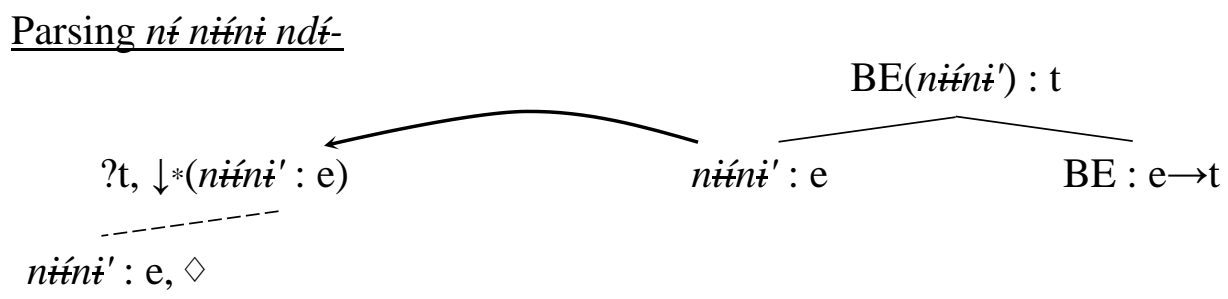

The tree in (80) is the same as (76) since it has been built up based on the copula $n \dot{t}$, the post-copula focus, and the subject marker on the auxiliary. Indeed, we propose that in these future tense clefts, the rest of the parse continues in the same manner as for a simple verb form - with the auxiliary form here analogous to the pre-stem tenseaspect marker (e.g., íó in the examples above). The auxiliary, therefore, provides a subject-predicate structure. The presence of this structure resolves the unfixed node as a subject node. The auxiliary also induces a metavariable $U$ at the predicate node.

\section{Parsing né nínti ndt́-rít}

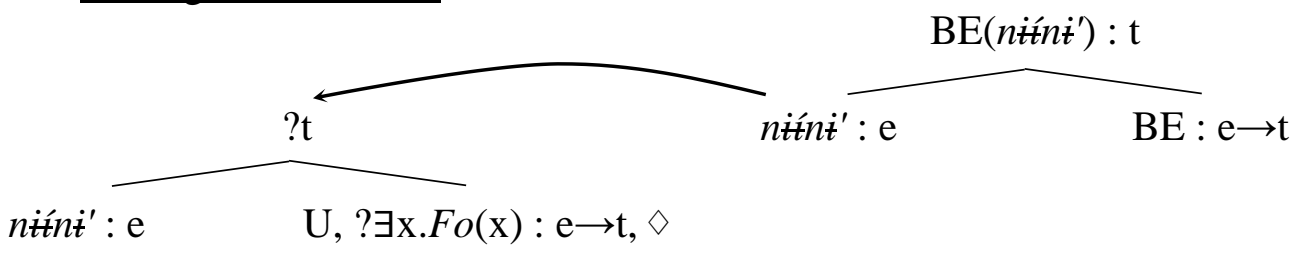

Now, the infinitival verb form kánya 'fell' is processed, projecting a propositional structure with a subject and an object argument slot. The subject argument slot can harmlessly collapse with the previously created subject node (i.e., the node already annotated with nitni'), identifying correctly the subject of the verb.

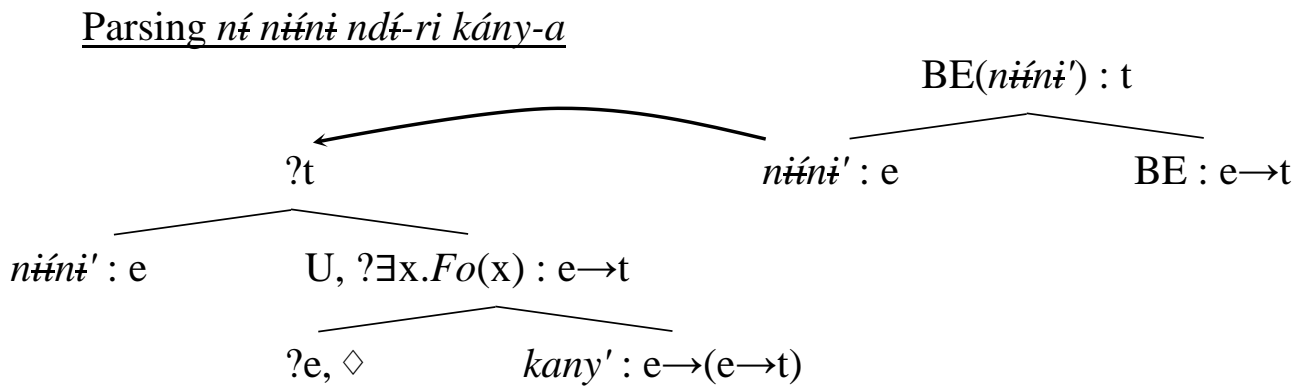


This is the accepted version of a final article which will be published by Elsevier in Language Sciences. Final published version available at: 10.1016/j.langsci.2016.03.003

Accepted Version downloaded from SOAS Research Online: http://eprints.soas.ac.uk/22203/

Finally, the object element $\boldsymbol{t}$ - $h \boldsymbol{t} \boldsymbol{m t} \boldsymbol{t}$ - $t i$ 'this tree' is parsed, and ELIMINATION applies, compiling the annotations as in (83).

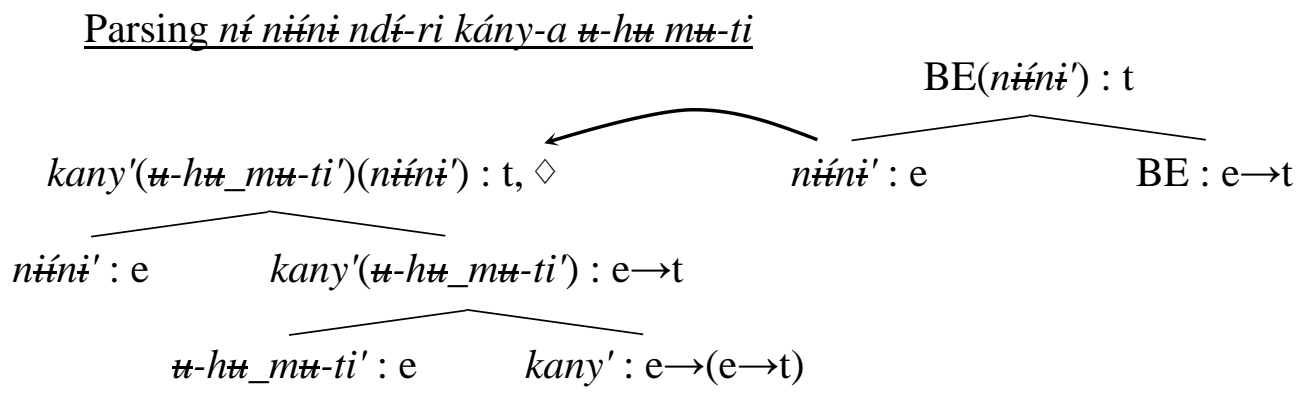

The current node, marked with the pointer $\diamond$, is annotated with the asserted content of the string parsed nú nínt ndt́-ri kány- $a \boldsymbol{t}$ - $h \boldsymbol{t} m \boldsymbol{m t}$ - $t i$ 'It is me that will fell this tree.'

Rangi is unusual in that declarative main clauses in the immediate future tense and general future tense exhibit verb-auxiliary order. Whilst this comparatively and typologically unusual word order is not the main target of this article, our analysis is extended to this construction type. Consider a (non-clefted) future tense construction such as (84).

$$
\begin{aligned}
& \text { háánd-an-íise vi-ryo } \text { t-ht } m w \text {-aáká } \\
& \text { plant-FV SM.1 }{ }^{\text {st }} \text {.SG-AUX 8-millet DEM-3 3-year } \\
& \text { 'I will plant millet this year.' }
\end{aligned}
$$

The verb haanda 'plant' appears clause-initially and is projected onto an unfixed node, reflecting the structurally underspecified relation of the infinitival verb to the rest of the tree (Author 2012). ${ }^{26}$ This node remains unfixed until the auxiliary form is parsed and the first fixed structure is introduced into the tree. The analysis developed above for clefts in combination with the past analysis of Rangi future tense constructions also accounts for why the verb-auxiliary ordering is not possible in cleft constructions, as illustrated in (85).

$$
\begin{aligned}
& \text { (85) *nt́ níní kány-a ndt́-rí } t \text {-htt mtt-ti } \\
& \text { COP } 1^{\text {st }} \text {.SG.PP cut-FV SM. } 1^{\text {st }} \text {.SG-AUX DEM-3 3-tree } \\
& \text { Int. 'It is me that will fell this tree.' }
\end{aligned}
$$

With the post-copula element already annotating an unfixed node, the projection of an additional unfixed node by the infinitival verb form is not licit. This would result in two unfixed nodes: one induced by the clefted element ní nítin and the other induced by the infinitive kány. These nodes would collapse onto each other as they would be identical in terms of tree logic, but the descriptions holding at the two nodes would be incompatible, violating the Unique Unfixed-Node Constraint (69).

\footnotetext{
${ }^{26}$ Infinitival verbs in Rangi, and Bantu more widely, exhibit both nominal and verbal properties: when an infinitive is encountered as the first element of the utterance (as in a Rangi future tense construction), its role as either a subject (nominal) or a complement of a verb is not yet ascertained. As such, it is proposed that the infinitive has an unspecified relation to the root node and annotates an unfixed node until the auxiliary is parsed thereby providing a fully-specified node address. The reader is referred to Author $(2012,2015)$ for additional details of this formal analysis.
} 
The constraint is also the basis for the prohibition of multiple foci in Rangi (in contrast to Japanese). With the focus projected onto an unfixed node, no additional focus can be introduced since this would also necessarily be projected onto an unfixed node. The Unique Unfixed-Node Constraint (69) states that at most one unfixed node of the same locality type can be present at a time. In an instance in which there are two (or more than two) foci, they encode distinct formulae and the node descriptions will be inconsistent.

Our analysis reflects the observed parallels between clefts and relatives which have been noted in a number of Bantu languages (e.g., Kempson et al. 2011, Cheng \& Downing 2013: 141). In DS terms, as in the analysis of relative clauses, the focal interpretation in clefts is expressed via a pair of LINKed trees, where the content of a focus is required to be present in the emergent tree by imposing a term-sharing requirement. This analysis, based on an unfixed node and a LINK relation, captures the general properties of Rangi clefts, whilst the Unique Unfixed-Node Constraint, a corollary of the tree-logic, is the basis for dealing with (i) the seemingly idiosyncratic inversion found in future tense clefts and (ii) the ban on multiple foci with distinct grammatical functions (unlike Japanese). ${ }^{27}$

\section{Coda: Towards a Dynamic Typology}

This article has developed an account of Japanese and Rangi clefts. After describing the features of Japanese clefts through the provision of new data on the case-marking of foci, a description of Rangi clefts (which has previously been unavailable in the literature) was also made. An explicit account of these findings has been provided from the perspective of how an interpretation is constructed incrementally online, as formalised within Dynamic Syntax (DS).

A cleft in Japanese consists of (i) a presupposition clause which is nominalised by the particle no and topicalised by the particle $w a$, (ii) a focused type-e item which may be case-marked $\left(\right.$ cleft $\left._{+} \mathrm{C}\right)$ or caseless $\left(\right.$ cleft $\left._{-}\right)$, and (iii) the copula $d a$ which appears at the end of the string. Expanding Author's (2013) account, we presented a uniform analysis of clefts ${ }_{+C}$ and clefts $-\mathrm{C}$. A cleft string is mapped onto the identical tree regardless of whether a focus is case-marked or caseless, the difference lying in the way in which an unfixed node for a focus is resolved: if a case particle is present, the node is resolved lexically, otherwise, it is resolved non-lexically by UNIFICATION. This uniform analysis explains the seemingly idiosyncratic features of multiple foci and the associated case-marking patterns. Specifically, it predicts the case particle distribution where only the final focus can be caseless. This is a natural reflex of the incremental parsing process: an unfixed node must be immediately resolved before another unfixed node is induced. As UNIFICATION may be used only for the final focus, an unfixed node for any non-final focus must be resolved by a case particle.

Further confirmation of our analysis is obtained by extension to the cleft data in the unrelated language, Rangi. A Rangi cleft employs the copula $n \dot{t}$ which appears clause-initially and a type-e focus item which appears immediately after the copula. We modelled Rangi clefts by recourse to LINKed trees with the LINK relation ensuring the flow of information between the main and the presupposition trees. A

\footnotetext{
${ }^{27}$ The analysis of coordinated focus cluster is not provided in this article. Footnote 7 suggests that coordination could be handled by virtue of LINK (Cann et al. 2005).
} 
requirement that a copy of the term be found in the LINKed tree is posited as is an unfixed node annotated with the information provided by the focus element. The rest of the cleft string is parsed in the standard fashion with lexical input combining with general actions to establish a propositional tree. The alternation between pre- and post-verbal auxiliary placement in the future tense, as well as the prohibition on multiple foci in Rangi clefts, are accounted for by the presence of the unfixed node as part of the parsing strategy, thereby prohibiting the co-occurrence of multiple unfixed nodes of the same locality type with incompatible content annotations.

One of the points that can be taken away from our account is that these distinct constructions in unrelated languages are handled in similar terms. The morphological and syntactic properties of clefts differ in the two languages. First, the ordering of the copula and the focus is different: in Japanese, the ordering is focus-copula while in Rangi it is copula-focus. Second, the focus sequence is positioned clause-finally in Japanese while it appears clause-initially in Rangi. Third, whereas multiple foci are permitted in Japanese (albeit in restricted contexts), these are never possible in Rangi unless the putative multiple foci constitute a coordinated (essentially unitary) nominal phrase. In spite of these differences, it is by recourse to the same basic principles of tree-logic and clause structure that the properties of clefts in the two languages are modelled appropriately. In this account, the alternation between pre- and post-verbal auxiliary placement in Rangi, for example, can therefore be seen as analogous to the behavior of multiple foci in Japanese in that both are captured in terms of the Unique Unfixed-Node Constraint, a corollary of the tree-logic. In this way, language-specific patterning follows from a universal constraint on parsing. The Unique Unfixed-Node Constraint thus proves itself to be both a natural reflex of the system and a powerful tool for constraining incremental tree-growth.

Having established a formal account of clefts in Japanese and Rangi, further avenues for research could explore the extent to which a similar analysis - or at least similar principles - is extended to clefts in other languages. Kempson et al. (2011) propose a similar analysis for clefts in siSwati under which the focus annotates a typee node LINKed to the main tree. Wei \& Kempson (2011) also make crucial use of LINK relations in dealing with Chinese clefts. Together with the insights stemming from these works, the present article suggests a dynamic typological model of clefts, where cross-linguistic parallelisms/differences are reduced to the way a cleft string is parsed left-to-right and an interpretation is updated accordingly.

\section{Acknowledgements}

The first author's part of this work was supported by Hankuk University of Foreign Studies Research Fund of 2016. The second author's work was funded by the Arts and Humanities Research Council and a British Academy Postdoctoral Fellowship. We gratefully acknowledge the support provided by these organisations. The second author also received invaluable assistance from the University of Dar es Salaam and the Commission for Science and Technology, Tanzania. We would like to thank Ash Asudeh, Stergios Chatzikyriakidis, David Cram, Mary Dalrymple, Ruth Kempson, Jieun Kiaer, and Lutz Marten for comments and discussion of a number of the topics contained herein, as well as Leo Mavere, Paulo Kijuu, and Yovin Maingu for assistance with data collection and insights on their language. 
This is the accepted version of a final article which will be published by Elsevier in Language Sciences.

Final published version available at: 10.1016/j.langsci.2016.03.003

Accepted Version downloaded from SOAS Research Online: http://eprints.soas.ac.uk/22203/

\section{References}

Blackburn, P. \& Meyer-Viol, W. 1994. Linguistics, logic, and finite trees. Bulletin of Interest Group of Pure and Applied Logics 2, 2-39.

Bouzouita, M. 2011. Future constructions in Medieval Spanish. In Kempson, R. et al. (eds.) The Dynamics of Lexical Interfaces. Stanford: CSLI Publications, pp. 91-132.

Bouzouita, M. \& Chatzikyriakidis, S. 2009. Clitics as calcified processing strategies. Proceedings of the LFG09 Conference. Stanford: CSLI Publications, pp. 188-207.

Bresnan, J. \& Mchombo, S. 1987. Topic, pronoun, and agreement in Chichewa. Language 63, 741-782.

Cann, R. 2006. Semantic underspecification and the pragmatic interpretation of $b e$. In von Heusinger, L. (ed.) Where Semantics Meets Pragmatics. Oxford: Elsevier, pp. 13-48.

Cann, R. 2011. Towards an account of the English auxiliary system. In Kempson, R. et al. (eds.) The Dynamics of Lexical Interfaces. Stanford: CSLI Publications, pp. 279-317.

Cann, R., Kempson, R., and Marten, L. 2005. The Dynamics of Language. Oxford: Elsevier.

Chatzikyriakidis, S. 2010. Clitics in Four Dialects of Modern Greek. PhD thesis, King's College London.

Cheng, L. \& Downing, L. 2013. Clefts in Durban Zulu. In Hartmann, K. \& Veenstra, T. (eds.) Cleft Structures. Amsterdam: John Benjamins, pp. 141-64.

Cho, S., Whitman, J., and Yanagida, Y. 2008. Clefts in Japanese and Korean. In Bane, M. et al. (eds.) Proceedings from the Annual Meeting of Chicago Linguistics Society 44 (1). Chicago: Chicago Linguistics Society, pp. 61-77.

Chomsky, N. 1965. Aspects of the Theory of Syntax. Cambridge, MA: MIT Press.

Chomsky, N. 1981. Lectures on Government and Binding. Holland: Foris.

Chomsky, N. 1995. The Minimalist Program. Cambridge, MA: MIT Press.

Creissels, D. \& Godard, D. 2005. The Tswana infinitive as a mixed category. In Müller, S. (ed.) Proceedings of the $12^{\text {th }}$ International Conference on Head-Driven Phrase Structure Grammar. Stanford: CSLI Publications, pp. 70-90.

Dalrymple, M. 2001. Lexical Functional Grammar. New York: Academic Press.

Davidson, D. 1967. The logical form of action sentences. In Rescher, N. (ed.) The Logic of Decision and Action. Pittsburgh: University of Pittsburgh Press, pp. 81-95.

Demuth, K. 1990. Subject, topic and Sesotho passive. Journal of Child Language 17, 67-84.

Dunham, M. 2004. On the verbal system in Langi, a Bantu language of Tanzania (F.33). Studies in African Linguistics 33 (2), 199-234.

Fukui, N. \& Sakai, H. 2003. The visibility guideline for functional categories. Lingua 113, 321-75.

Gregoromichelaki, E. 2006. Conditionals in Dynamic Syntax. PhD thesis, King's College London.

Gregoromichelaki, E., Kempson, R., Purver, M., Mills, G., Cann, R., Meyer-Viol, W., and Healey, P. 2011. Incrementality and intention-recognition in utterance processing. Dialogue and Discourse 2 (1), 199-233.

Harbour, D. 2008. Klivaj predika, or predicate clefts in Haitian. Lingua 118 (7), 85371.

Heim, I. \& Kratzer, A. 1998. Semantics in Generative Grammar. Oxford: Blackwell. 
This is the accepted version of a final article which will be published by Elsevier in Language Sciences.

Final published version available at: 10.1016/j.langsci.2016.03.003

Accepted Version downloaded from SOAS Research Online: http://eprints.soas.ac.uk/22203/

Hiraiwa, K. \& Ishihara, S. 2012. Syntactic metamorphosis. Syntax 15 (2), 142-80.

Hoji, H. 1990. Theories of Anaphora and Aspects of Japanese Syntax. Ms., University of Southern California.

Howes, C. 2012. Coordinating in Dialogue. PhD thesis, Queen Mary University of London.

Kahraman, B., Sato, A., Ono, H., and Sakai, H. 2011. Incremental processing of gapfiller dependencies. In Otsu, Y. (ed.) Proceedings of the Twelfth Tokyo Conference on Psycholinguistics. Tokyo: Hituzi Publishing, pp. 133-47.

Kamide, Y. 2006. Incrementality in Japanese sentence processing. In Nakayama, M. et al. (eds.) The Handbook of East Asian Psycholinguistics, Vol. 2. Cambridge: Cambridge University Press, pp. 249-56.

Kempson, R., Cann, R., and Marten, L. 2013. Treegrowth dynamics. Studies in Linguistics 6, 49-81.

Kempson, R., Gregoromichelaki, E., and Howes, C. 2011. The Dynamics of Lexical Interfaces. Stanford: CSLI Publications.

Kempson, R. \& Kurosawa, A. 2009. At the syntax-pragmatics interface. In Hoshi, H. (ed.) The Dynamics and Mechanism of Language. Tokyo: Kuroshio Publishers, pp. 47-84.

Kempson, R., Marten, L., and Thwala, N. 2011. SiSwati clefts. In Kempson, R. et al. (eds.) The Dynamics of Lexical Interfaces. Stanford: CSLI Publications, pp. 23-60.

Kempson, R., Meyer-Viol, W., and Gabbay, D. 2001. Dynamic Syntax. Oxford: Blackwell.

Kiaer, J. 2014. Pragmatic Syntax. London: Bloomsbury Publishing.

Kitagawa, C. \& Ross, C. 1982. Prenominal modification in Chinese and Japanese. Linguistic Analysis 9, 19-53.

Kizu, M. 2005. Cleft Constructions in Japanese Syntax. New York: Palgrave.

Koizumi, M. 2000. String vacuous overt verb raising. Journal of East Asian Linguistics 9, 227-85.

Kuwabara, K. 1996. Multiple wh-phrases in elliptical clauses and some aspects of clefts with multiple foci. In Koizumi, M. et al. (eds.) MIT Working Papers in Linguistics 29. Cambridge, MA: MIT Press, pp. 97-116.

Link, G. 1983. The logical analysis of plurals and mass terms. In Bauerle, R. et al. (eds.) Meaning, Use, and the Interpretation of Language. Berlin: Walter de Gruyter, pp. 302-23.

Marten, L. 2002. At the Syntax-Pragmatics Interface. Oxford: Oxford University Press.

Marten, L. 2011. Information structure and agreement. Lingua 121, 787-804.

Montague, R. 1973. The proper treatment of quantification in ordinary English. In Hintikka, J. et al. (eds.) Approaches to Natural Language. Dordrecht: Kluwer, pp. 221-42.

Nakamura, H., Yoshimoto, K., Mori, Y., and Kobayashi, M. 2009. Multiple subject constructions in Japanese. In Hattori, H. et al. (eds.) JSAI 2008. Berlin: Springer, pp. 103-18.

Nishiyama, Y. 2003. Nihongo Meishiku-no Imiron-toGoyouron. (The semantics and pragmatics of Japanese noun phrases) Tokyo: Hituzi Publishing.

Pritchett, B. L. 1992. Grammatical Competence and Parsing Performance. Chicago, IL: University of Chicago Press. 
This is the accepted version of a final article which will be published by Elsevier in Language Sciences.

Final published version available at: 10.1016/j.langsci.2016.03.003

Accepted Version downloaded from SOAS Research Online: http://eprints.soas.ac.uk/22203/

Pustet, R. 2003. Copulas. Oxford: Oxford University Press.

Sag, I. \& Wasow, T. 2011. Performance-compatible competence grammar. In Borsley, R. \& Borjars, K. (eds.) Non-transformational Syntax. Oxford: Blackwell, pp. 359-77.

Sag, I., Wasow, T., and Bender, E. 2003. Syntactic Theory, $2^{\text {nd }}$ edn. Stanford: CSLI Publications.

Stegen, O. 2001. To be, or not to be. Ms., SIL Tanzania.

Stegen, O. 2006. Participatory research, TAM functions, and dialect survey among the Rangi. Ms., SIL Tanzania.

Takano, Y. 2002. Surprising constituents. Journal of East Asian Linguistics 11, $243-$ 301.

Visser, M. A. 1989. The syntax of the infinitive in Xhosa. South African Journal of African Languages 9 (4), 154-85.

Watters, J. R. 2000. Syntax. In Heine, B. \& Nurse, D. (eds.) African Languages. Cambridge: Cambridge University Press, pp. 194-230.

Wei, L. \& Kempson, R. 2011. Chinese cleft structures and the dynamics of processing. Ms., Beijing Jiaotong University, King's College London.

Yicheng, W. 2011. Towards a dynamic typology of passives. In Kempson, R. et al. (eds.) The Dynamics of Lexical Interfaces. Stanford: CSLI Publications, pp. 129-59.

Zerbian, S. 2006. Expression of Information Structure in the Bantu Language Northern Sotho. Berlin: ZAS.

\section{Authors' addresses}

Tohru Seraku

seraku@ hufs.ac.kr

Department of Japanese Interpretation and Translation,

Hankuk University of Foreign Studies

Language and Literature Building,

81 Oedae-ro, Mohyeon-myeon,

Cheoin-gu, Yongin-si, Gyeonggi-do, 449-791,

KOREA.

Hannah Gibson

hg6@soas.ac.uk

Department of Linguistics,

SOAS, University of London,

Thornhaugh Street, Russell Square,

London, WC1H OXG,

UNITED KINGDOM. 